\title{
CEO Turnover in a Competitive Assignment Framework
}

\author{
Andrea L. Eisfeldt*
}

\author{
Camelia M. Kuhnen ${ }^{\dagger}$
}

\author{
February 2010
}

\begin{abstract}
This paper considers the empirical stylized facts about CEO turnover in the context of a competitive assignment model in which CEOs and firms form matches based on multiple characteristics. CEOs are viewed as hedonic goods with multidimensional skill bundles. Likewise, firms' production functions have heterogeneous weights on CEO skills such as firm-specific knowledge, ability to grow sales, and ability to cut costs. There exists a competitive market for CEOs, whose wages are determined analogously to the prices of the hedonic goods in Rosen (1974). The competitive assignment framework with multiple skill dimensions is able to capture several stylized facts which are not explained by existing theories. For example, in our model, both poor relative performance and poor absolute performance are associated with higher rates of CEO turnover. Relative performance evaluation matters even though there is no agency problem or learning, and overall industry performance affects turnover as well. Our model also makes predictions about the type and pay of the replacement manager conditional on turnover type which are consistent with patterns we document empirically. For example, managers who are fired are more likely to be replaced by industry outsiders than are managers who quit or retire. Moreover, replacement managers in these cases earn significantly more than the incumbent. To document pay and replacement type as a function of the type of turnover event, we construct a large dataset describing turnover events during the period 1992-2006, including the type of turnover event, and the characteristics and pay of the replacement manager.
\end{abstract}

*Department of Finance, Kellogg School of Management, Northwestern University, 2001 Sheridan Rd., Evanston, IL 60208-2001, a-eisfeldt@northwestern.edu

${ }^{\dagger}$ Department of Finance, Kellogg School of Management, Northwestern University, 2001 Sheridan Rd., Evanston, IL 60208-2001, c-kuhnen@kellogg.northwestern.edu. 


\section{Introduction}

This paper considers the empirical stylized facts about CEO turnover in the context of a competitive assignment model in which CEOs and firms form matches based on multiple characteristics. CEOs are viewed as hedonic goods with multidimensional skill bundles. Likewise, firms' production functions have heterogeneous weights on CEO skills such as firm-specific knowledge, ability to grow sales, and ability to cut costs. There exists a competitive market for CEOs, whose wages are determined analogously to the prices of the hedonic goods in Rosen (1974). The competitive assignment framework with multiple skill dimensions is able to capture several stylized facts which are not explained by existing theories. For example, in our model, both poor relative performance and poor absolute performance are associated with higher rates of CEO turnover. Relative performance evaluation matters even though there is no agency problem or learning, and overall industry performance affects turnover as well. Our model also makes predictions about the type and pay of the replacement manager conditional on turnover type which are consistent with patterns we document empirically. For example, managers who are fired are more likely to be replaced by industry outsiders than are managers who quit or retire. Moreover, replacement managers in these cases earn significantly more than the incumbent. To document pay and replacement type as a function of the type of turnover event, we construct a large dataset describing turnover events during the period 1992-2006, including the type of turnover event, and the characteristics and pay of the replacement manager.

There is considerable controversy about both CEO pay and CEO retention. Recently, papers such as Tervio (2008) and Gabaix and Landier (2008) have shown that viewed through the lens of competitive assignment models based on that in Rosen (1981), the observed high levels of CEO pay can be seen as natural outcomes of the joint distribution of talent and firm sizes. ${ }^{1}$ These papers constitute one response to the argument that the observed high level of CEO pay is a result of entrenched managers earning excessive rents (eg. Bebchuk and Fried (2004)).

In this paper, we ask whether the implications of a competitive assignment model can also be used to understand the flip side of CEO pay, namely CEO turnover. As with

\footnotetext{
${ }^{1}$ See also the early contribution by Lucas (1978), the competitive assignment model of the distribution of earnings in Sattinger (1979) and the review of the implications of competitive assignment models for earnings in Sattinger (1993). Dicks (2009) studies the implications of the assignment model of CEO pay for corporate governance.
} 
CEO pay, there is a debate over whether boards optimally decide to terminate or retain their manager. Several papers have asked whether considering the board's monitoring problem in the moral hazard and asymmetric information setting of Holmstrom (1982) and Gibbons and Murphy (1990) can explain observed patterns in turnover events and have shown that indeed poor performing managers are less likely to be retained. ${ }^{2}$ However, others (Jenter and Kanaan (2006) and Kaplan and Minton (2006)) have recently noted that industry conditions also contribute significantly to the termination decision, with poor industry conditions leading to a higher likelihood of turnover. In this paper, we illustrate how a competitive assignment model like those used to explain the distribution of CEO pay can be used to understand these observed empirical patterns of CEO turnover.

That decisions about CEO replacement can be driven by industry conditions and observable managerial characteristics can be seen clearly in current events. The future of the CEOs in the beleaguered US auto and financial services industries is being debated by the media and influenced by government interventions. However, not all CEOs face the same termination risk. For example, the US government forced GM's Rick Wagoner out by threatening to withhold further bailout money, but allowed Chrysler's Robert Nardelli to stay on. In an article about the replacement, the Wall Street Journal ${ }^{3}$ noted that, "Unlike Mr. Wagoner, who had been at the helm of GM since 2000, Mr. Nardelli is considered an auto-industry outsider". Similarly, there has been speculation that CEOs in the financial services industry, such as Vikram Pandit of Citigroup and Ken Lewis of Bank of America might also be ousted. ${ }^{4}$ However, given the complexity of the assets of certain financial institutions, firm-specific and industry specific knowledge may be critical to weathering financial crises and this may make outsider replacements untenable.

Our theoretical framework is based on a competitive assignment environment, where both the CEO and the firm optimize over the relative value of preserving their current match vs. pursuing their outside option. We model managers as hedonic goods with multiple characteristics, or skills. Likewise, firms have production functions whose weights on these skills may vary both in the cross section and over time. We show that shocks to the weights on skills such as firm-specific knowledge, ability to grow sales, and ability

\footnotetext{
${ }^{2}$ See for example Barro and Barro (1990), Gibbons and Murphy (1990), and Warner, Watts, and Wruck (1988).

${ }^{3}$ March 302009 issue, available on-line at http://online.wsj.com/article/SB123836090755767077.html.

${ }^{4}$ In fact, in September 2009 Ken Lewis announced that he will step down as the CEO of Bank of America.
} 
to cut costs, can generate turnover that is correlated with both poor relative and absolute performance. We argue that the competitive assignment model can also be used to understand the choice between an inside and outside replacement manager, and the corresponding pay and performance of the replacement. Viewing managers as hedonic goods allows one to consider how industry shocks might drive CEO turnover since weights on particular skills are likely to be correlated within industries. In future work, it may also be interesting to use a hedonic pricing model to understand which of the scarce skills general managers possess drives the high pay of talented CEO's. For example, Murphy and Zabojnik (2004), Murphy and Zabojnik (2007) and Frydman (2005) have used the hypothesis that general managerial skills have increased in importance relative to firm-specific skills to understand the rise in CEO pay over time. However, in this paper we focus mainly on turnover events, and study the dynamics of CEO pay only around turnover events.

Our empirical work contributes to the existing literature by studying a large dataset of CEO replacements we construct to describe turnover events which occur during the period 1992-2006. We collect information regarding both the reason for the incumbent CEO's departure and the identity and background of the new CEO. We study the effect of firm and industry conditions on the likelihood of turnovers classified as forced departures, potential quits or retirements. We similarly document the determinants of the choice of whether the replacement CEO will be a firm insider, industry insider, or firm and industry outsider. Empirically, a large fraction of turnover events cannot be classified as either firings or quits. Interestingly, in the context of a competitive assignment model where separations occur when total surplus becomes negative, this is also the case. Under most reasonable theoretical definitions of fires vs. quits, a large fraction of separations in data generated by the model would remain unclassified.

First, we show that our dataset confirms earlier findings that poor industry stock returns and low firm stock performance relative to the industry increase the likelihood of forced turnover. Controlling for firm relative to industry stock returns, we find that low firm relative to industry return on assets (ROA) also increases the likelihood of forced turnovers. Thus, real variables contain additional information about CEO performance. Not surprisingly, retirements and potential quits appear to be much less affected by relative firm performance than are forced turnovers. Poor firm performance still significantly increases the likelihood of these types of turnovers too, but the magnitude of the effect is less than a quarter of the effect of poor performance on the likelihood of forced turnovers. 
Our empirical work supports the idea that the independent effects of industry conditions on turnover may be driven by the fact that industry shocks can change what type of manager is optimal. For example, industries which experience a decline in the long term trend of return on assets, have lower stock returns, or have lower average ROA also experience more forced turnovers. Importantly, firms that force departures are more likely to choose a replacement CEO from outside the industry, consistent with the idea that the firm desires to match with a new manager with a different skill set than that of the incumbent.

We also show that industry conditions affect the CEO's decision to depart the firm voluntarily. Potential quits are more frequent in industries with down-trending ROA, and with lower average stock returns and ROA, suggesting that in those industries the outside option of the CEO of leisure or perhaps joining private firms is more valuable than the expected payments received by staying with the firm during the industry downturn. Retirements are less frequent in industries with higher employment growth, possibly indicating that part of the rent captured by active CEOs comes from empire building (e.g. managing organizations with many employees).

Replacement CEOs are significantly more likely to come from outside the firm and outside the industry when the firm does poorly in terms of stock returns and return on assets, or when the industry has low ROA, which are instances where typically the incumbent CEO is fired. Replacement CEOs are more likely to come from inside the firm if the turnover event was due to retirement or voluntary departure rather than forced turnover. The pay of replacement CEOs is highest in situations where the incumbent was fired and the new CEO is an outsider.

Our paper builds on the results of a large body of work ${ }^{5}$ on CEO turnover. One of the most documented facts is that relative performance evaluation (RPE) matters for CEO turnover: the probability of CEO turnover is negatively related to the performance of the firm relative to the industry (Barro and Barro (1990), Gibbons and Murphy (1990)) or to the market (Warner, Watts, and Wruck (1988)).

However, RPE does not seem to be the only driver of managerial changes. Jenter and Kanaan (2006) document that CEOs are more likely to be dismissed from their job after bad industry and bad market performance, and in light of these findings argue that RPE cannot be the sole determinant of CEO turnover. They suggest two hypotheses consistent with the empirical results. First, corporate boards may commit systematic attribution

\footnotetext{
${ }^{5}$ See Murphy (1999) for a review of the literature on CEO compensation and turnover.
} 
errors and credit or blame the CEO for performance caused by factors outside their control. Second, firm performance in bad times may be more revealing about CEO skill than performance in good times. In our model, the relevance of industry conditions for whether or not a CEO is forced out comes from considering the firm and CEO as parties in a match whose actions depend on their respective outside options. The data seem to support this idea since the type of turnover event helps to predict the type of replacement chosen. In particular, forced turnovers are associated with replacement by outsiders.

Several papers have focused on the relationship between corporate governance, compensation and CEO turnover. Huson, Parrino, and Starks (2001) find that the frequency of forced turnover and of outside succession increased over time during 1971 to 1994, and that board characteristics influence the likelihood of these events. Kaplan and Minton (2006) argue that the CEO turnover rate during 1992-2005 is higher than previously found for the prior two decades (11.8\% versus $10 \%)$ and attribute this to boards becoming increasingly more sensitive to the CEO's performance. ${ }^{6}$ Peters and Wagner (2007) suggest that this recent increase in turnover has lead to a significant increase in CEO pay, as executives face a higher risk of losing their jobs.

The role of industry conditions on CEO turnover has not received much attention in the literature. This may be because historically, the literature on CEO turnover has focused on the role of boards as monitors of the firm and has attempted to ascertain their effectiveness in this role. ${ }^{7}$ Notable exceptions are Parrino (1997) and Eisfeldt and Rampini (2008). Parrino (1997) argues that intra-industry CEO appointments are less costly and performance measures are more precise in homogeneous industries, and, consistent with this argument, finds that the likelihood of forced turnover and of an intraindustry appointment increase with industry homogeneity. Eisfeldt and Rampini (2008) show how aggregate business cycle conditions can drive CEO turnover and compensation in a principal agent environment where managers have private information about their skill. Their focus, however, is on external turnover due to mergers and acquisitions.

\footnotetext{
${ }^{6}$ Kaplan and Minton (2006) also document that CEO turnover is related to industry performance relative to the stock market, and performance of the overall stock market, but do not provide an interpretation for these results, as they are not the focus of the paper.

${ }^{7}$ We thank Robert Parrino for this helpful historical perspective on the literature.
} 


\section{Model}

Our model is similar to the competitive assignment models used to explain the rise in, and high levels of CEO compensation, except that in those models skill is one-dimensional and there is only one industry. In fact, we believe we are the first to develop a competitive assignment model with two industries, or markets, although the two market set up might be useful for modeling marriage markets, general labor markets, or real estate markets as well. Having two industries is useful for studying turnover, but it does add complication since firm and manager outside options depend on conditions in both industries. Similarly, one dimensional heterogeneity across managers and firms is a useful simplification which allows one to derive managers' wage profiles as a function of talent in a straightforward manner.

Our modeling strategy is most closely related to Tervio (2008) who uses the model from Sattinger (1979) in which skills are one-dimensional, skill and size distributions are continuous, and firm size and CEO ability are complementary in production, to analytically describe the relationship between CEO talent, firm size, and CEO pay. Gabaix and Landier (2008) employ extreme value theory to show quantitatively that such a model can explain the rise in and level of CEO pay. Finally, in a closely related model, Murphy and Zabojnik (2004) and Murphy and Zabojnik (2007) incorporate firm-specific vs. general skill by modeling firms as only being able to deploy a fraction of a new CEO's ability. The remaining fraction represents firm-specific skill which can only be deployed by incumbent managers. Murphy and Zabojnik use their model to explain the rise in CEO pay by an increase in the importance of general managerial skills through comparative statics over this fraction. Our model and solution methods will closely follow Tervio (2008) adapted to our set up with multidimensional heterogeneity and more than one industry.

There are two dates, zero and one. At each date, managers will be matched to firms via competitive assignment. To fix ideas, it is useful to first examine the decision problems of a single firm and manager at a single date. For this, we consider the decision problems of a manager and a firm who are currently matched in a competitive assignment economy. Neither the firm, nor the manager can commit to honoring long term contracts, so each must earn at least the value of their outside option in each period in order for the match to continue. The dynamics of optimal managerial compensation induced by agency problems when long term contracts are feasible is the focus of many recent theoretical 
papers. ${ }^{8}$ Although some of these papers do contain results about contract termination, their main focus is on compensation dynamics rather than CEO turnover. For the most part termination in these models is rare, and is largely used as a stick to provide incentives with rather than treated as an object of interest in and of itself. The limited focus on CEO turnover in the theoretical literature is in contrast to the large empirical literature on turnover discussed above.

We consider a firm $i$ which produces output using capital and the managerial input from manager $j$ according to:

$$
a_{i}\left(m_{j}\right) k^{\alpha}
$$

where $a_{i}\left(m_{j}\right)$ is the productivity of capital when firm $i$ employs manager $j$, and $\alpha \in[0,1]$. This productivity is given by (slightly abusing notation):

$$
a_{i}\left(m_{j}\right)=\sum_{s=1}^{S} \theta_{i, s} a_{j, s}
$$

where $\theta_{i, s}$ is a weight which describes the importance of skill $s$ in determining the productivity of capital deployed in firm $i$ and $a_{j, s}$ is the level of ability of manager $j$ in skill $s$. Thus the productivity of manager $j$ employed at firm $i$ is the inner product of manager $j$ 's skill levels and firm $i$ 's skill weights. These weights vary over time and across firms. Moreover, these weights are likely to be correlated within industries, and subject to common shocks. For example, growing firms may have high weights on skills such as building and motivating a sales force, and firms in mature industries may place higher weights on cost cutting. Firms which can fund growth or operating leverage internally may not have a high weight on the ability to raise external finance, whereas firms needing to access capital markets might. Similarly, the importance of firm-specific vs. general skills may vary in the spirit of the evidence documented by Frydman (2005) for the time series of all firms. The abilities of managers may also vary over time. In particular, managers

\footnotetext{
${ }^{8}$ See for example, DeMarzo and Fishman (2007a), DeMarzo and Fishman (2007b), He (2007), DeMarzo, Fishman, He, and Wang (2009), He (2009), Sannikov (2008), and Lustig, Syverson, and Van Nieuwerburgh (2009). Sannikov (2008) considers the effects of variation in firm and managerial outside options on the agency costs of providing incentives. DeMarzo, Fishman, He, and Wang (2009) consider how exogenous variables affect the degree of agency costs and hence the dynamics of managerial compensation. Lustig, Syverson, and Van Nieuwerburgh (2009) study how managerial outside options affect the division of rents between managers and firm owners over time and study the induced distributions of managerial compensation. He (2007) focuses on the effects of hidden savings on compensation dynamics. Edmans and Gabaix (2009) provide a survey of how these and other recent theories can explain "pay-for-luck".
} 
may gain firm-specific abilities through learning by doing during their tenure with the firm. Although it is interesting to consider the decision by the manager to invest in accumulating different skills, for simplicity here we will assume that abilities are fixed and leave a study of that investment decision for future work. ${ }^{9}$ Bertrand and Schoar (2003) document managerial fixed effects in management style, consistent with abilities being somewhat rigid. For it to be optimal to replace a manager with a suboptimal skill set, we need to have that there are at least investment costs, adjustment costs, or time to build for managerial skills, which seems reasonable. The value or total surplus created by firm $i$ when it is matched with manager $j$ is

$$
V \equiv a_{i}\left(m_{j}\right) k^{\alpha}
$$

To keep things simple, there is no labor other than the managerial input in our model.

Since we assume that there is no commitment on the part of the manager, the manager will always need to earn a value inside the match equal to the value of their outside option. The manager can quit, or they can retire. We assume that there is a market for managers in which the per period hedonic price of a manager is given by the market value of that manager's ability bundle, which we denote by $w_{j}$. This market is in the spirit of that formalized in Rosen (1974) and Lancaster (1966). Rosen (1974) contains a description of the technical assumptions which determine the properties of the hedonic price function. If skill bundles are recombinable, and there is no arbitrage, this function will be linear but these assumptions seem strong for the CEO market and so we expect the price function to be nonlinear. Moreover, because bundles cannot be dismantled, the price of any particular skill will depend on the joint distributions of and demands for all skills. For this reason, when one is interested in the distribution of CEO pay it is convenient to assume that skills are one-dimensional, as in Sattinger (1979) and Tervio (2008). Here, we depart from this assumption but simplify our general model in order to solve for managerial wages. We illustrate ideas by solving a simple example in Subsection 2.1. Then, in Subsection 2.2 we solve a two industry version of our model with skill levels and weights carefully specified to allow us to solve the model for turnover and wages in a parsimonious way. We base our solution method on that in Tervio (2008)) adapted to incorporate the additional heterogeneity and the existence of an alternative industry for

\footnotetext{
${ }^{9}$ In a recent paper Giannetti (2009) presents a model where compensation is designed to incentivize managers to invest in firm-specific skills.
} 
managers.

If the manager can either stay at his current employer, quit for his next best employment option, or retire, then the manager's outside option is:

$$
V^{m_{j}} \equiv \max \left\{w_{j}, R\right\}
$$

where $R$ is the value of retiring.

The firm's owners will also need to be paid their outside option. The firm can fire the manager and hire a replacement, or it can liquidate. The firm's outside option is given by:

$$
V^{f_{i}} \equiv \max \left\{\max _{n}\left\{a_{i}\left(m_{n}\right) k^{\alpha}-\left(V^{m_{n}}\right)\right\}, L\right\} .
$$

The left hand argument is the value the firm receives with the optimal replacement manager, where $a_{i}\left(m_{n}\right)$ and $V^{m_{n}}$ are defined analogously to the productivity of manager $j$ at firm $i$ and the outside option of manager $j$ defined above as a function of the market prices of manager $n$ 's skills. The right hand argument, $L$, is the liquidation value of the firm.

The current match will dissolve if total surplus from the match is negative, in other words if the value created by the current match after payments to capital and labor, minus the manager's outside option, minus the firm's outside option, is negative, i.e. if:

$$
\begin{aligned}
& \left(a_{i}\left(m_{j}\right) k^{\alpha}\right)-\left(\max \left\{w_{j}, R\right\}\right) \\
-\quad & \left.\left(\max _{\max _{n}}\left\{a_{i}\left(m_{n}\right) k^{\alpha}-\left(V^{m_{n}}\right)\right\}, L\right\}\right)<0
\end{aligned}
$$

or,

$$
V-V^{m_{j}}-V^{f_{i}}<0
$$

This condition is analogous to what Murphy and Zabojnik (2004) describe as the "make or buy" tradeoff, except that skills are multidimensional.

\subsection{Two Firm Example}

We now consider CEO turnover and pay in a simple stylized equilibrium example of our model. There are two firms (A and B) in the industry, and four potential managers ( $\mathrm{w}, \mathrm{x}$, $y$, and z), each with three skills, namely, industry or firm specific knowledge, sales growth ability, and cost cutting ability. There are two dates, 0 and 1. Production is linear (i.e., 
$\alpha=1$ ), the interest rate is zero, there is no labor, and capital $k$ is fixed. At date 0, Firm A has 3 units of capital and $\theta$ weights $(1,1,0)$ on the 3 skills respectively. Firm B has 1 unit of capital and $\theta$ weights $(0,1,0)$ on the 3 skills respectively. Thus, both firms weight sales growth ability, and firm A weighs industry specific skills more heavily (it produces a more complex good, for example). Manager w has skill levels $(1,1,0)$, manager $\mathrm{x}$ has skill levels $(0,1,0)$, manager y has skill levels $(0,0,1)$, and manager $\mathrm{z}$ has skill levels $(0$, $0,3)$, for the 3 skills respectively. Thus, manager w has industry specific skills and sales growth skills, manager $\mathrm{x}$ has sales growth skills, and managers y and $\mathrm{z}$ have cost cutting skills. Managers who do not get hired may deploy their non-industry specific skills in another industry which has weights equal to one on sales growth and cost cutting and capital equal to $\frac{1}{2}$. Firms in this alternative industry face free entry and earn zero profits, thus, managers' who are not hired have outside options equal to $\frac{1}{2} \sum_{s=2: 3} a_{s}$.

An equilibrium at date 0 is an allocation of managers to firms, and wages paid to managers, such that no manager and no firm prefers an alternative allocation. ${ }^{10}$ One such equilibrium is as follows: Firm B hires manager x, produces 1 unit of output, pays the manager $\frac{1}{2}+\epsilon$ in order to make the manager prefer to work at firm B instead of in the alternative industry, and has profits of $\frac{1}{2}-\epsilon$. Firm A hires manager w, produces 6 units of output, pays the manager $\frac{1}{2}+2 \epsilon$ in order to make the manager prefer to work at firm $\mathrm{A}$ instead of firm $\mathrm{B}$, and has profits of $5 \frac{1}{2}-2 \epsilon$.

At the beginning of time 1 , a shock changes the weights on the skill bundles at firm A and B. The formerly young industry is now mature and firms A and B should cut costs instead of growing sales. At date 1 , Firm A has 3 units of capital and $\theta$ weights $(1,0$, 1 ) on the 3 skills respectively. Firm $B$ has 1 unit of capital and $\theta$ weights $(0,0,1)$ on the 3 skills respectively. Due to the shock to the skill weights, output in the industry falls from 7 units to 3 units. Firms may choose to terminate their managers and replace them. First, imagine that only managers (w, x, and y) are available. In this case, one equilibrium is as follows: Firm B hires manager y, produces 1 unit of output, pays the manager $\frac{1}{2}+\epsilon$ in order to make the manager prefer to work at firm B instead of in the alternative industry, and has profits of $\frac{1}{2}-\epsilon$. Firm A decides to retain its manager, w, produces 3 units of output, pays the manager $\frac{1}{2}+\epsilon$ in order to make the manager prefer to work instead of being unemployed for zero pay, and makes profits of $2 \frac{1}{2}-\epsilon$. Thus, in this case, only the relatively poorly performing firm fires its manager. However, if

\footnotetext{
${ }^{10}$ See Tervio (2008) for the analogous conditions in the equilibrium of the one-dimensional skill case when skills and firm size distributions are continuous.
} 
manager $\mathrm{z}$ is available, a candidate equilibrium is: Firm $\mathrm{B}$ hires manager y, produces 1 unit of output, pays the manager $\frac{1}{2}+\epsilon$ in order to make the manager prefer to work at firm $\mathrm{B}$ instead of in the alternative industry, and has profits of $\frac{1}{2}-\epsilon$. Firm A hires manager $\mathrm{z}$, produces 9 units of output, pays the manager $2 \frac{1}{2}+2 \epsilon$ in order to make the manager prefer to work at firm $\mathrm{A}$ instead of firm $\mathrm{B}$ and makes profits of $6 \frac{1}{2}-2 \epsilon$. Thus, the industry shock may cause both firms to turn over their CEO's.

Firms will not want to pay for skills they do not find valuable, so when a shock changes skill weights they are likely to look outside the industry, where these new skills have been previously productively deployed, for their replacement. Notice also that if the outside option of deploying general skills in other industries is higher than that of deploying industry specific skills, the outsiders will tend to be more highly paid relative to their contribution to output. In the example, consider firm A's choice of replacement. To dominate the existing manager, the outsider replacement needs to be able to generate considerably higher output since all of that output is generated by skills with positive market prices. As a result, the firm will require much higher output under the new manager in order to be able to pay the manager the higher required wage and still increase profits. Thus, when an outsider is hired, output increases significantly and so does CEO compensation.

\subsection{Two Industry Economy}

The basic assignment model of Sattinger (1979), Tervio (2008), and Gabaix and Landier (2008) is built upon the following three simplifying assumptions: First, skills and firm characteristics are one-dimensional (managers have talent and firms have a size), second, the distributions of talent and firm size are continuous, and third, firm size and talent are complements. Assuming skills have only one dimension significantly simplifies the analysis because wages do not depend on the joint distributions of managerial skills and firm skill weights. However, if one chooses the distributions carefully, and adopts the assumptions that skill distributions and firm skill weights are continuous and firm skill weights and managerial skill levels are complementary, then the analytical techniques used in Tervio (2008) can be applied to solve for equilibrium wage and profit profiles. For example, one could assume that general (priced) skills and skill weights are mutually exclusive. In this case, the demand for a particular manager depends only on one priced characteristic. Essentially, the model becomes one with separate markets for each 
dimension of CEO talent. We will not assume that skill weights are mutually exclusive, for reasons discussed below, but it is a useful starting point for thinking about a multiindustry, multi-dimensional skill model. We will, however, make convenient assumptions to reduce the complexity of firm and managerial outside options.

There are two dates, zero and one. There are two industries, A and B, and two types of managers, $\mathrm{x}$ and z. All firms have capital stocks equal to one. There are measure one of firms in each industry, and measure one of each type of manager. Thus, there will be no unemployment. Similarly, to keep things managable, we will not consider retirement or liquidation here although they would be interesting extensions. ${ }^{11}$. As in the example above, skill levels and weights have three dimensions, namely, firm specific skill, sales growth skill, and cost cutting skill, respectively. Managers have a firm specific skill level greater than zero if they are incumbents at that firm, and zero otherwise. General skill levels are fixed characteristics of managers. Type $\mathrm{x}$ managers have sales growth skills distributed uniformly between zero and two, and have zero cost cutting skills. Type $\mathrm{x}$ managers have firm specific skills $a_{0}^{x}=a_{1}^{x}+1$ iff they work at their incumbent firm in industry A. The fact that firm specific skills are greater than general skills enables firm specific costs to have the effect of a fixed cost of firing. The opportunity cost of losing firm specific skills will lead to what appears to be relative performance evaluation since only the poorest performing managers will be fired. One implication of this is that cutoff levels for firing should be lower in industries where managers have high levels of firm specific skill and this seems to make sense. ${ }^{12}$ We have,

$$
\begin{aligned}
& a_{0}^{x} \sim U(1,3), \\
& a_{1}^{x} \sim U(0,2),
\end{aligned}
$$

and $a_{2}^{x}=0$. Type $z$ managers have $a_{0}^{z}$ equal to one iff they work at their incumbent firm in industry B. Type z managers have cost cutting skills distributed uniformly between zero and two, and have zero sales growth skills. We then have,

$$
a_{2}^{z} \sim U(0,2),
$$

\footnotetext{
${ }^{11}$ One could consider varying the outside options of the least productive operating firm $\pi_{0}$ and least talented employed manager $w_{0}$ in the single market equilibrium. We discuss this in section 2.3 in reference to our empirical work [to be completed]

${ }^{12}$ This is basically applying the intuition used in Frydman (2005) and Murphy and Zabojnik (2007) used to explain the time series of turnover events to the cross section.
} 
and $a_{1}^{z}=0$. Again, firm level productivity will be given by the inner product of managerial skill levels and firm skill weights. Firm skill weights can change over time. In particular, we will consider the effects on turnover and managerial compensation of a date 1 shock to the skill weights in industry A. At time zero, firms in industry A have skill weights as follows:

$$
\theta_{0}^{A} \sim U(2,4), \quad \theta_{1}^{A} \sim U(1,3), \text { and } \quad \theta_{2}^{A}=0 .
$$

We assume that $\theta_{0}^{A}$ and $\theta_{1}^{A}$ are perfectly correlated so that the firm with the highest firm specific skill weight also has the highest general skill weights. When ordered between zero and one, the oneth firm has the highest weights and is the most productive. Firms in industry B have constant skill weights as follows:

$$
\theta_{0}^{B} \sim U(0,1), \quad \theta_{1}^{B} \sim U(0,1), \text { and } \quad \theta_{2}^{B} \sim U(0,1)
$$

Notice that industry A is more productive than industry B, and that even the firm with the lowest sales growth weight in industry A has a weight at least as great as the most productive firm in industry B. Industry B also values both general skills. It is a generalist industry, and one that employs a pool of potential replacements for industry A. Since in practice CEO-CEO job transitions are rarely observed, one might think of the industry $\mathrm{B}$ managers as division managers in large firms.

At date zero, managers are assigned to firms via competitive assignment. Given our assumptions, at this date the economy reduces to two distinct competitive assignment markets, and the equilibrium assignment is given by the equilibrium assignments in each of the markets separately. All managers of type $x$ will work in industry $A$, and all managers of type $z$ will work in industry $B$. We assume that the economy at date $t=-1$ is described by the same parameters as those at time zero, so that all managers have $a_{0}>0$ since they will work for their incumbent firms.

We now describe output, managerial compensation, and profits in the two industries. Our analysis closely follows that in Tervio (2008) and it may be useful for the reader to refer to Section I of that paper for additional details. As in his paper, it will be convenient to consider the inverse distribution functions for skill levels and skill weights. Managers and firms are ordered on the unit interval as described above so that for each manager type $y \in\{x, z\}$ and each skill type $n \in\{0,1,2\} a_{n}^{y}[i]$ is the skill level of a quantile $i$ type $y$ manager and the derivative of the inverse distribution satisfies $a_{n}^{y \prime}[i] \geq 0$ for each skill type, with strict inequality for general skills. For each manager and skill type, if $F_{a}^{y}$ is 
the cumulative distribution of $a$ for type $y$, then the profile of $a$ is given by

$$
a^{y}[i]=a^{y} \quad \text { s.t. } \quad F_{a}^{y}(a)=i .
$$

Basically, $a^{y}[i]$ gives the ability level of the $i^{t h}$ type y manager. The inverse distribution functions for firms' skill weights are defined analogously for industries A and B.

In each industry, the equilibrium assignment must satisfy two types of constraints. First, the sorting constraints state that each firm must prefer hiring its manager at their equilibrium wage to hiring any alternative manager at that replacement manager's equilibrium wage. Second, the participation constraints state that all firms and individuals must earn their outside option for opportunities outside of industries A and B. In our economy, we set these outside options to be equal to zero, and leave the study of variation in liquidation and retirement options to future research. We have the following constraints where boldface type is used to denote vectors:

$$
\begin{aligned}
V\left(\mathbf{a}^{x}[i], \boldsymbol{\theta}^{A}[i]\right)-w^{x}[i] & \geq V\left(\mathbf{a}^{x}[j], \boldsymbol{\theta}^{A}[i]\right)-w^{x}[j] \quad \forall i, j \in[0,1] \quad S C(i, j) \\
V\left(\mathbf{a}^{x}[i], \boldsymbol{\theta}^{A}[i]\right)-w^{x}[i] & \geq 0 \quad \forall i, j \in[0,1] \quad P C \quad \boldsymbol{\theta}^{\boldsymbol{A}}[i] \\
w^{x}[i] & \geq 0 \quad P C \quad \mathbf{a}^{\mathbf{x}}[\mathbf{i}]
\end{aligned}
$$

Analogous sorting constraints must hold across industries, but we ignore them at date 0 since they will not be binding. They will bind for some agents at date 1 . Note also that the only binding sorting constraints within an industry are those which consider hiring the next best manager. Moreover, since firm specific skills are not valued outside the firm, and firms in industry $\mathrm{A}$ at time zero have $\theta_{2}=0$, one only needs to consider the effects of $a_{1}$ and $\theta_{1}$. As a result, the date zero economy reduces to two economies of the type studied in Tervio (2008). Analogous constraints must be satisfied in industry $\mathrm{B}$ which will employ type $z$ managers. The participation constraints will bind for the lowest ability manager and the lowest productivity firm.

We now solve for wages and profits at time zero. Regrouping the sorting constraints for types $i$ and $i-\epsilon$ and dividing by $\epsilon$ yields:

$$
\frac{V\left(\mathbf{a}^{x}[i], \boldsymbol{\theta}^{A}[i]\right)-V\left(\mathbf{a}^{x}[i-\epsilon], \boldsymbol{\theta}^{A}[i]\right)}{\epsilon} \geq \frac{w^{x}[i]-w^{x}[i-\epsilon]}{\epsilon}
$$


Taking the limit as $\epsilon \rightarrow 0$ we get the slope of the wage profile for type $x$ managers: ${ }^{13}$

$$
w^{x \prime}[i]=V_{\mathbf{a}}\left(\mathbf{a}^{x}[i], \boldsymbol{\theta}^{A}[i]\right) \cdot \mathbf{a}^{x \prime}[i]
$$

Finally, integrating, and adding the binding participation constraint yields the wage profile:

$$
w^{x}[i]=w^{0}+\int_{0}^{i} V_{\mathbf{a}}\left(\mathbf{a}^{x}[j], \boldsymbol{\theta}^{A}[j]\right) \cdot \mathbf{a}^{x \prime}[j] d j
$$

Again, since firm specific skills are not valued outside the firm, and firms in industry A at time zero have $\theta_{2}^{A}=0$, to compute wages one only needs to consider the effects of $a_{1}^{x}$ and $\theta_{1}^{A}$. Note that the sorting constraints could have been written from the manager's perspective, and an analogous profile for profits can be obtained as follows: ${ }^{14}$

$$
\pi^{A}[i]=\pi^{0}+\int_{0}^{i} V_{\theta}\left(\mathbf{a}^{x}[j], \boldsymbol{\theta}^{A}[j]\right) \cdot \theta^{A \prime}[j] d j
$$

Using the distributions for $\boldsymbol{\theta}^{A}$ and $\mathbf{a}^{x}$, the definition $V\left(\mathbf{a}^{x}[i], \boldsymbol{\theta}^{A}[i]\right)=\mathbf{a}^{x}[i] \cdot \boldsymbol{\theta}^{A}[i] k^{\alpha}$, and the fact that $k=1 \forall i$, we have that output in industry $\mathrm{A}$ is given by: ${ }^{15}$

$$
V^{A}(i, i)=1+6 i+8 i^{2}
$$

wages, or managerial outside options are given by, ${ }^{16}$

$$
w^{x}(i)=2 i+2 i^{2}
$$

and firm profits are given by ${ }^{17}$

$$
\pi^{A}(i)=2+6 i+6 i^{2} .
$$

\footnotetext{
${ }^{13}$ Note that because of the discontinuity in the value of $a_{0}$ as managers change firms one technically can't use this argument for firm specific skills. Firm specific skills are unpriced and have a wage of zero. One can think of taking the limit only over the part of $V$ which comes from general skills, and then adding the output and profits from general skills separately.

${ }^{14}$ Here again, due to the discontinuity in $a_{0}^{x}$ across firms, one can integrate over the general skills contribution to profits and add the contribution of firm specific skills separately.

${ }^{15}$ To compute output, note that output equals $\theta_{0}(i) a_{0}(i)+\theta_{1}(i) a_{1}(i)+\theta_{2}(i) a_{2}(i)$ and use the distributions for skills and skill weights to compute output as a function of $i$. In particular, note that $\theta_{0}^{A}=1+2 i$, $a_{0}^{x}=1+2 i, \theta_{1}^{A}=1+2 i, a_{1}^{x}=2 i, \theta_{2}^{A}=0$, and $a_{2}^{x}=0$.

${ }^{16}$ For wages, note that $a_{1}^{x}[j]=2 j$ so that $a_{1}^{x \prime}[j]=2$, and $\theta_{1}^{A}(j)=1+2 j$ so $\int_{0}^{1} \theta_{1}^{A}(j) d j=j+j^{2}$. $j^{2}$.

${ }^{17}$ For profits from general skills, note that $\theta_{1}^{A}(j)=1+2 j$ so $\theta_{1}^{A \prime}(j)=2$ and $a_{1}^{x}(j)=2 j$ so $\int_{0}^{1} a_{1}^{x}(j) d j=$
} 


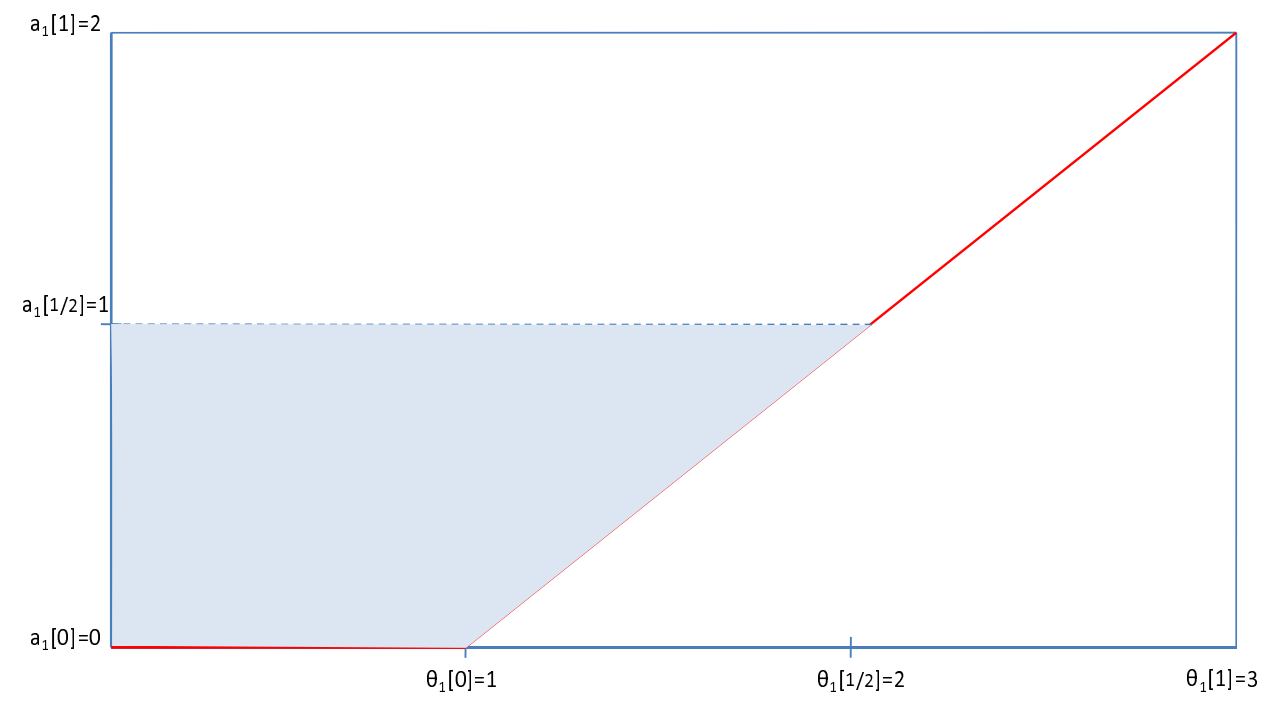

Figure 1: Industry A General Skill Output, Wages, and Profits.

When the retirement option has zero value, then $w=V^{m}$ where $V^{m}$ is described in Section 2 and used in section 2.3. Similarly, when liquidating has zero value, then $\pi=V^{f}$.

Figure 1 graphs output, wages, and profits in industry A. Take for example, firm $\frac{1}{2}$ who is matched with manager $\frac{1}{2}$. Output is 6 . Of this, 1.5 is paid to the manager and 4.5 is retained by the firm. However, note that the manager receives the majority of the portion of output created from general skills, which is 2 . These wages are graphed in figure 1 as the shaded area to the left of the matching function for the $\left(\frac{1}{2}, \frac{1}{2}\right)$ match.

Similarly, for industry B, which in equilibrium employs managers of type $z$, we have: ${ }^{18}$

$$
V^{B}(i, i)=3 i^{2}
$$

wages, or managerial outside options are given by, ${ }^{19}$

$$
w^{z}(i)=i^{2}
$$

and firm profits are given by ${ }^{20}$

$$
\pi^{B}(i)=2 i^{2}
$$

At time 1, industry A receives a shock to skill weights that induces turnover in

\footnotetext{
${ }^{18}$ To compute output, note that $\theta_{0}^{B} \sim U(0,1), a_{0}^{z}=1, \theta_{1}^{B}=i, a_{1}^{z}=0, \theta_{2}^{A}=i$, and $a_{2}^{z}=2 i$.

${ }^{19}$ For wages, note that $a_{2}^{x}[j]=2 j$ so that $a_{2}^{x \prime}[j]=2$, and $\theta_{2}^{A}(j)=j$ so $\int_{0}^{1} \theta_{2}^{A}(j) d j=\frac{1}{2} j^{2}$.

${ }^{20}$ For profits from general skills, note that $\theta_{2}^{A}(j)=j$ so $\theta_{1}^{A \prime}(j)=1$ and $a_{2}^{z}(j)=j$ so $\int_{0}^{1} a_{2}^{z}(j) d j=\frac{1}{2} j^{2}$.
} 


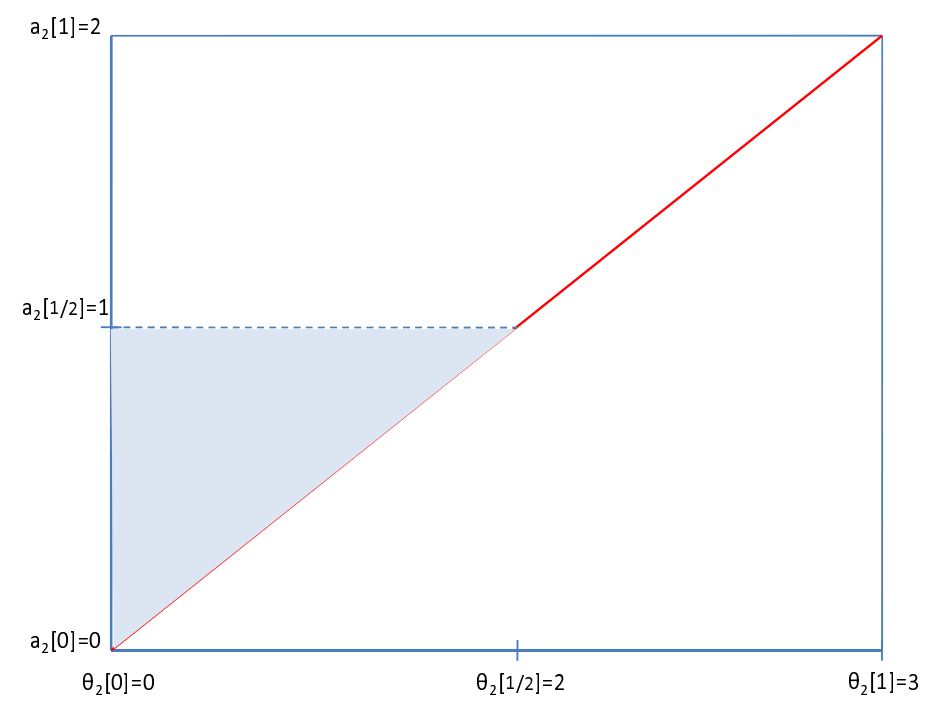

Figure 2: Industry B General Skill Output, Wages, and Profits.

industry A and industry B. We will examine turnover (firings, quits) and pay at date 1 as a result of this shock. Imagine that industry A had been a growing industry but has now matured and firms thus need to focus on cost cutting instead of sales growth. This change translates into a change in the skill weights in industry A. In particular, we examine the effects of a switch in which $\theta_{1}^{A}$ and $\theta_{2}^{A}$ exchange values. Thus, $\theta_{1}^{A}$ becomes zero for all firms, and $\theta_{2}^{A}$ becomes positive and is distributed uniformly across firms between one and three. Weights in industry $\mathrm{B}$ do not change.

We show that the resulting reallocation of managers is as follows: The most talented managers in industry A remain with their firms. They are incumbents. There is a cutoff level of talent below which all managers in industry A are fired and reallocate to industry B. Call the index of this talent level $i_{A}^{*}$. Because industry A is more productive, the managers at the top end of industry $B$ will quit and reallocate to replace the fired managers at the bottom of industry A. Call the index of the talent level above which type $z$ managers quit industry $\mathrm{B}$ to work in industry $\mathrm{A} i_{B}^{*}$ and note that $i_{B}^{*}=1-i_{A}^{*}$. The fired managers from industry A will go to work in industry B.

We solve for the competitive assignment equilibrium at date 1 as follows: First, we guess that there is a cutoff rule for managerial turnover as described above. Then, conditional on this rule, we compute equilibrium wages and output. We can then solve for the cutoff value, and verify that we have found an equilibrium.

[To be completed] 


\subsection{Discussion}

Considering again the general model, there are several channels through which changes in exogenous variables such as industry conditions might drive total surplus below zero and thereby drive CEO turnover. Throughout the description of the model we used simple notation and suppressed the dependence of skill weights, skill prices, the pool of replacement managers, the value of retirement and liquidation and the productivity of capital on industry conditions. However, we think that such conditions likely affect all of these variables. Consider first the potential effects of a deterioration in industry conditions on the outside option of the firm. As the industry declines, the optimal managerial skill bundle may change as it did in our example, for instance to more heavily weigh cost cutting or the ability to access capital markets. Firms may find it profitable to fire incumbent managers and hire managers with the newly more desirable bundle. Thus, a model like the one described can generate more forced turnover or firings when industry conditions are poor under what seem to be reasonable assumptions about the relationship between the firm's outside option and what is going on in the industry. Next, consider how industry conditions might change the outside option of the manager and lead to managers quitting for better jobs or retiring. Changes in industry conditions can change skill prices and lead the manager to leave for greener pastures. Finally, industry conditions can change the relative value of retirement through affecting the disutility of work and the value of retirement compensation packages.

Industry conditions affect turnover in the competitive assignment model and in the data. However, firm relative to industry performance is the most important predictor of observing an instance of forced turnover, both in our data and in that of previous studies. The finding that RPE apparently has such a large empirical contribution to turnover seems to suggest that there is quite a bit of private information and/or learning about $\mathrm{CEO}$ ability. However, note that even without private information one might observe what would appear to be RPE driven turnover in data generated by a model like the one described. In our example, depending on available managers' skills, it is possible that only the poorly performing firm would choose to replace its manager after the industry shock. Thus, finding that RPE drives turnover does not show that boards are effectively dealing with a problem of asymmetric information. The empirical relationship between poor performance and turnover may simply be due to variation in the importance or level of firm or industry specific skills which may lead only the poorest performing firms to seek replacements. Alternatively, there may be other fixed costs of replacement which would 
also lead to performance thresholds for firing managers. On the other hand, the converse is also true. Even if the data did not find such strong support for RPE, one could still not conclude that boards were not using RPE to gauge talent and effort if other drivers for turnover also exist. We believe that both learning about unobservable managerial skills, and shocks to demands for observable talents, are important contributors to CEO turnover.

Explicitly considering the outside options of both managers and firms in our competitive assignment framework illustrates another, perhaps surprising feature of such a model which is also consistent with the data. In the model, as in the data, it is actually quite difficult to label a separation as a "quit" or "fire". Since empirically separations are typically labeled as quits or fires by utilizing news stories as we do here, one might think that the large fraction of turnovers which can neither be labeled as quits or fires are simply misclassified due to lack of information. One might think that if one had perfect data, that all separations should be able to be labeled one way or the other. However, even in data generated by the model, quite reasonable theoretical definitions of quits and firings would imply that for a large fraction of separations, the agent who initiated the separation is ambiguous. Separations occur when the total surplus from the current match is negative. As discussed, this can occur for many reasons on the part of the firm and the manager, both of whose outside options vary over time, or it can be that the total value of the match declines. Furthermore, the outside options of the firm and the manager, as well as the value created by the match depend on the same variables, namely, skill weights and prices.

We discuss this ambiguity in the context of one specific definition of "quits" vs. "fires" but note that the model permits others. We introduce time subscripts and suppress individual agent subscripts to define a separation as follows:

Definition $1 A$ separation occurs in the current period when a match satisfies the following two conditions:

Condition $1 V_{t}-V_{t}^{m}-V_{t}^{f}<0$

and

Condition $2 V_{t-1}-V_{t-1}^{m}-V_{t-1}^{f}>0$.

Now, consider defining a separation as initiated by one agent (either the manager or the firm) if that agent would choose to remain in the match with the current match value 
and the current outside option of the other agent, but with their own lagged outside option. This separation must satisfy conditions 1 and 2 as well as either

Condition $3(\mathrm{Q}) V_{t}-V_{t-1}^{m}-V_{t}^{f}>0$

if the separation is a quit, and

Condition 4 (F) $V_{t}-V_{t}^{m}-V_{t-1}^{f}>0$

if the separation is a fire. Note that conditions 1 and Q together simply say that $V_{t}^{m}>$ $V_{t-1}^{m}$, while conditions 1 and $\mathrm{F}$ together simply say that $V_{t}^{f}>V_{t-1}^{f}$. These two inequalities are not mutually exclusive, so clearly many separations would be unclassified under this definition. We can, however, refine this definition further.

Add to the definition above that the initiating agent would not want to remain in the match even given the current match value, that agent's current outside option, and the other agent's lagged outside option. If conditions $\mathrm{Q}$ and $\mathrm{F}$ are associated with quits and fires, these new conditions basically state that quits must also not be firings, and likewise firings must also not be quits. In other words, they require that the separation also satisfy

Condition $5(\neg \mathbf{F}) V_{t}-V_{t}^{m}-V_{t-1}^{f}<0$

if the separation is a quit, and

Condition $6(\neg \mathrm{Q}) V_{t}-V_{t-1}^{m}-V_{t}^{f}<0$

if the separation is a fire.

Then, a quit can be defined as a separation which satisfies Q and $\neg$ F. Combining these two conditions, and condition 1 with condition $\mathrm{Q}$ yields the following definition of a quit:

Definition $2 A$ separation is a quit if $V_{t}^{m}>V_{t-1}^{m}$ and $V_{t}^{m}-V_{t-1}^{m}>V_{t}^{f}-V_{t-1}^{f}$.

Similarly, a fire can be defined as a separation which satisfies F and $\neg$ Q. Combining these two conditions, and condition 1 with condition $\mathrm{F}$ yields the following definition of a firing:

Definition 3 A separation is a fire if $V_{t}^{f}>V_{t-1}^{f}$ and $V_{t}^{f}-V_{t-1}^{f}>V_{t}^{m}-V_{t-1}^{m}$. 
Even these very loose definitions permit separations that cannot be classified in cases in which the total value of the match drives the surplus negative and outside options remain unchanged. More strict definitions of quits and fires, such as the one given by conditions $\mathrm{Q}$ and $\mathrm{F}$ only, or requiring a quit to satisfy $V_{t}^{m}>V_{t-1}^{m}$ and $V_{t}^{f} \leq V_{t-1}^{f}$ and requiring a fire to satisfy $V_{t}^{f}>V_{t-1}^{f}$ and $V_{t}^{m} \leq V_{t-1}^{m}$, would lead to even more ambiguous separations. However, note that in the model, as in the data, the type of replacement manager, and the compensation of that manager, would yield additional information about the type of separation observed.

\section{Data}

We use four main sources of data: Execucomp for the name and compensation of the CEOs of 2779 publicly traded companies during 1992-2006, CRSP/Compustat for stock returns and accounting data for these firms, the industries they belong to, and the market in general, the Bureau of Economic Analysis for industry and aggregate data (referring to both public and private firms), and Factiva for news stories published in a three-year window around CEOs departures. The information in Factiva allows us to determine the reason why a CEO left and to identify where the replacement CEO came from. ${ }^{21}$

We identify 2068 instances where a CEO was replaced, and for which we know both the reason for the incumbent's departure, as well as where the new CEO came from. Of all replacements, $613(29.7 \%)$ are the result of a planned retirement decision, announced at least six months prior to the actual departure date, or of a health-related reason. Another 323 (15.6\%) replacements are instances where the incumbent CEO was forced out, according to newspaper stories related to the departure. The remaining $1132(54.7 \%)$ cases are those that do not fit in any of these two categories - retirements or firings and thus we will label them unclassified departures. These events include instances where the incumbent voluntarily left the firm, and therefore we also refer to them as potential quits. Since these unclassified departures are the residual category, one might expect them to behave like a weighted average of retirements and forced turnovers. This is true for some empirical relationships (for example the relationship between relative firm performance and the likelihood of turnover), but unclassified departures have some

\footnotetext{
${ }^{21}$ We are grateful to Dirk Jenter for providing us with the data in Jenter and Kanaan (2006) regarding whether or not a CEO was fired or chose to retire. We used those data to fill in some of the missing observations for which our Factiva search was not fruitful.
} 
distinct characteristics also. We discuss this more in section 4, but, for example, they have the strongest negative relationship of all turnover types with contemporaneous market returns.

Our definition of departure type is different from the algorithm described in Parrino (1997) and followed by several other papers, in two significant ways. First, and most important, the extant literature on turnover identifies just two types of departures: forced and unforced (the latter including retirements). However, since an employment relationship is the result of a two-sided matching process that depends on the conditions in the executive labor market, we allow for turnover to happen for three reasons: the firm chooses to terminate the match, the $\mathrm{CEO}$ chooses to terminate the match but is still active in the executive labor market, or the CEO leaves the executive labor market for exogenous reasons such as age and health. These three types of departure have different theoretical reasons and will be predicted by different variables in the empirical analysis.

Second, unlike Parrino (1997), we do not condition on the incumbent CEO's age to define a departure as forced or not. Parrino (1997) classifies as forced departures all cases where the CEO is younger than 60, and (1) related news stories do not report the reason for departure as involving death, poor health or the acceptance of another job, or (2) the firm reports the departure as a retirement, but does so less than six months before succession. We believe that it is possible that in some of these instances managers voluntarily quit the job - they were not fired, nor did they choose to leave the executive labor market (i.e. retire.) Hence, while in papers using the Parrino (1997) algorithm the age of the departing CEO is a significant and negative predictor of forced turnover because of the way forced turnovers are defined, in our analysis this mechanical relationship does not exist.

\section{Empirical Results}

The three novel theoretical predictions that we will test empirically are as follows:

(H1) When industry conditions deteriorate, forced turnover and voluntary quits are more likely to occur.

(H2) When industry conditions deteriorate, replacement CEOs are more likely to have skills different from those of departing CEOs.

(H3) The pay of CEOs reflects the market price of their skill bundles. 
In line with these predictions, the empirical evidence we document indicates that the type of CEO departure, as well as the type of CEO hired as a replacement and their pay depend strongly on the firm's need for strategy change and on the outside option of both the firm and the CEO.

In the analysis we build on the findings of a large empirical literature on CEO turnover. Typically in this literature, either the firm's stock return or the firm's return on assets (ROA), adjusted for industry performance, have been used to predict CEO turnover, and forced turnover in particular. For instance, Gibbons and Murphy (1990), Murphy (1999), Jenter and Kanaan (2006) and Kaplan and Minton (2006) use stock returns, while ROA (typically by itself and not in addition to the stock return) is used in Barro and Barro (1990), Parrino (1997), Huson, Parrino, and Starks (2001), and Huson, Malatesta, and Parrino (2004). The evidence in these papers indicates that relative performance evaluation (Holmstrom (1982)) is used to determine whether a CEO is fired ${ }^{22}$ or not: if the firm's performance (measured as stock return or ROA) relative to the industry is higher, the probability of the CEO being forced out is lower.

We replicate this result throughout our analysis. For instance, in Table 1 we show that lagged relative stock return performance (i.e. firm minus average industry return) is a significant and negative predictor of a CEO being fired. ${ }^{23}$ We strengthen this result by showing that a combination of multiple performance benchmarks determine the likelihood of a CEO being fired. A firm's stock return and its return on assets - measured relative to the industry - together contribute to the firing outcome. Since these RPE measures are noisy and not perfectly correlated signals of the quality of the CEO-firm match, they all should be inputs in the firing decision.

The second important result we replicate is one documented in Jenter and Kanaan (2006) and Kaplan and Minton (2006): firings seem to be more likely after bad industry and bad market performance, measured by stock returns. This effect is illustrated by the multinomial logit models of departure type in Table 1. Controlling for firm relative to industry returns, industry relative to market returns (Industry - MarketReturn ${ }_{t}$ ) and market returns (VWMarketReturn $_{t}$ ) during year $t$ (Panel A) and industry returns $\left(\right.$ VWFFIndustryReturn $n_{t}$ (Panel B) are significant negative predictors of the relative

\footnotetext{
${ }^{22}$ In some of the extant literature, data limitations did not allow for turnovers to be classified as forced or not forced, but the RPE hypothesis refers to firings, and not to other types of CEO departures.

${ }^{23}$ We also perform a robustness check by measuring annual returns over July-June instead of JanuaryDecember, and the results are similar.
} 
likelihood of the CEO being forced out versus there being no turnover during year $t+1 .^{24}$

Although these results have been documented previously, we provide a unique interpretation here. As our competitive assignment model suggests, industry conditions affect the CEO-firm match surplus and thus drive turnovers. We will now turn to the novel empirical findings we document, in light of the predictions of our theoretical framework.

\subsection{Match dissolution}

The first novel hypothesis of the competitive assignment framework that we test, (H1), states that when industry conditions deteriorate, forced turnover and voluntary quits are more likely to occur.

We first observe that turnover of all types, and forced turnover in particular, are relatively concentrated. Using the Fama French 48 industry classification system, we find that $50 \%$ of all instances of forced turnover occur in just seven industries: Business Services, Computers, Retail, Utilities, Chips, Machinery and Drugs. Overall turnover is also concentrated in several industries, although less so than forced turnover. The top $5 \%$ of 608 industry-year bins that our observations belong to account for $22 \%$ of all turnover events, and for 35\% of forced turnover. Since these CEO-firm match dissolution events are not uniformly distributed across industries and over time, we investigate what specific industry conditions may drive turnover.

Figures 3 and 4 show the relationships between the frequency of firings and potential quits, and various industry characteristics measured over $1993-2005 .{ }^{25}$ We use the Fama French 48 industry classification throughout this analysis. During thus time period, the average industry-level rates of forced turnover and potential quits are $1.69 \%$ and $6.21 \%$, respectively.

For each industry and each year, we classify the industry as having below-trend ROA if the industry ROA that year is lower than its three-year average. We then count the number of below-trend years for each industry during 1993-2005. As shown in Figure 3, the frequency of firings is significantly higher in industries with below-trend ROA during more years in the period of 1993-2005 $(p<0.01)$. One additional year of down-trending

\footnotetext{
${ }^{24}$ The negative relationship between the likelihood of forced turnover and either industry returns or industry relative to market returns is robust to defining lagged returns using July-June windows.

${ }^{25}$ Since our dataset ends in 2006 , the last year for which we can compute turnover rates is 2005 . Also, a large number of firms do not appear in Execucomp in 1992, and due to this incomplete coverage we drop data from 1992 in our analysis of industry conditions and time trends.
} 
ROA increases the frequency of forced turnover by $0.2 \%$ (from $1.69 \%$ to $1.89 \%$ in the average industry).

We also find that industries with lower average ROA have significantly higher firing rates during 1993-2005 ( $p<0.01)$. A one-standard deviation decrease in the ROA from $0 \%$ (for the average industry) to $-5 \%$ increases the firing rate by $0.6 \%$. Industries with lower annual value-weighted stock returns are characterized by higher firing rates $(p<0.1)$, whereas those with higher employment growth have more forced turnover $(p<0.01)$. The latter result is explained by the fact that in our sample there is a strong negative correlation between average employment growth in the industry and industry ROA during 1993-2005 ( $p<0.01)$.

An interesting question is whether there is a significant positive relationship between firing rates and the industry homogeneity index, as found by Parrino (1997) for the period 1969-1989. His result implied that it is easier to replace a CEO if there is a larger pool of suitable candidates to pick from. In unreported regressions, we do not find this positive correlation in our data. As suggested by Frydman (2005), however, the importance of firm (or industry-specific) skill has diminished over time, and nowadays general management skills are most desirable. This would explain why in the recent time period that we study, we no longer find that industry homogeneity (and thus, the availability of candidates with firm or industry-specific skills) is a determinant of forced turnover. Indeed, in a model such as ours, the within industry dispersion in stock returns might be quite small for an industry which is subject to strong common shocks to CEO skill weights, however, these common shocks would lead to turnover and the hiring of outsiders if industry-specific skills were relatively unimportant. ${ }^{26}$

Figure 4 shows that the frequency of unclassified departures (potential quits) is significantly higher in industries with more years of below-trend ROA and with lower valueweighted stock returns $(p<0.01)$. All these effects are economically significant. For instance, decreasing the annual industry-level stock return by one standard deviation (6.09\%) from the sample mean of $12.9 \%$ increases the frequency of quits by $0.73 \%$, a significant effect given that the average quits frequency is $6.21 \%$ in our data. We do not find a strong correlation between quits and industry employment growth.

While our theoretical framework is mainly focused on firings and quits, in reality many instances of turnover are retirements due to exogenous reasons such as age or

\footnotetext{
${ }^{26}$ We thank Robert Parrino for sharing with us the industry-level homogeneity index values for the period 1990-2006.
} 
health. In our data, the average industry-level rate of retirements is $3.32 \%{ }^{27}$ As shown in Figure 5, industry characteristics tend not to be significant drivers of the retirement frequency. The one marginally significant result is that the frequency of retirements is higher in industries with lower employment growth $(p<0.1)$. This indicates that retirement decisions may not be exogenous to the firm or aggregate conditions, as one might think. CEOs have some leeway in when they choose to retire, and may do so where their outside option is better than the payoff from staying with the firm. It is possible that retention payoffs are relatively less attractive in industries with lower employment growth, if empire-building is part of these payoffs.

To illustrate our main results regarding the link between industry conditions and CEO turnover - in particular, firings and quits - using simple statistics, we split observations based on quartiles of industry conditions. Figure 6 shows the frequency of turnover types as a function of industry conditions during 1993-2005. The firing rate is $0.5 \%$ in the top industry ROA quartile and $2.4 \%$ in the bottom quartile. The rate of potential quits is $4.8 \%$ in industries belonging to the quartile with the lowest number of ROA downtrending years, and $6.7 \%$ in those with the most prolonged ROA down-trend. The firing rate is also higher in industries in the lowest quartile of stock returns (1.7\%) than in those in the highest quartile (1.4\%), and in industries with higher employment growth. Retirement frequency is highest $(3.7 \%)$ in industries in the highest ROA quartile and lowest $(2.4 \%)$ in those in the lowest ROA quartile.

While these univariate results confirm the prediction that CEO-firm match dissolution depends on industry conditions, we further test this hypothesis in a multivariate setting using firm-year level data to control for potential confounds. This analysis reveals the effects of firm and industry conditions on CEO departures, which we document in the multinomial logit model in Table 2. The dependent variable is categorical and can have four values, indicating whether in a particular firm (a) there was no CEO change between years $t$ and $t+1$, (b) the CEO in place in year $t$ was fired and a new CEO took over in year $t+1$, (c) the CEO in place in year $t$ retired and a new CEO took over in year $t+1$ and (d) the CEO in place in year $t$ left for unknown reasons (potentially quit) and a new CEO took over in year $t+1$.

The results show that firings are more likely relative to there being no turnover, if the firm's stock return or ROA relative to the industry (Firm - IndustryReturn I $_{\mathrm{f}}$

\footnotetext{
${ }^{27}$ The overall turnover rate for the average industry, which includes firings, potential quits, as well as retirements is $11.98 \%$.
} 
and Firm - IndustryROA $A_{t}$ ) are lower, and if the industry has experienced low stock returns relative to the market (Industry-MarketReturn I $_{\text {) }}$ or a downturn in profitability

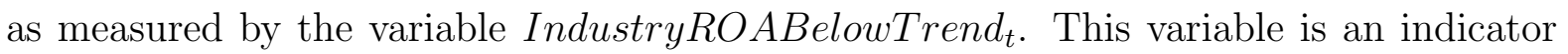
equal to 1 if the average ROA in the industry during the preceding three years is below its value during the preceding ten years. We interpret such an event as indicating a structural break in the profitability of the industry and as signal that the industry is experiencing bad times. These results are consistent with our hypothesis that when the firm and the industry experience a downturn, a change in strategy may be optimal hence the firm should dissolve the match with the current CEO by forcing him out.

We replicate the univariate result documented above that a higher employment growth in the industry in year $t$ correspond to a higher firing likelihood at time $t$. We measure industry employment growth using either CRSP/Compustat figures for publicly-traded companies, or the Bureau of Economic Analysis data for public and private companies classified using NAIC industry codes. Our results hold for either of these measures, as seen in Panels A and B of Table 2.

Unclassified departures are more likely to happen relative to there being no turnover if the firm's stock return, ROA or employment growth relative to the industry is lower, if the industry ROA is lower, and if the recent three-year industry ROA is below its tenyear trend, consistent with the univariate results documented earlier. As our theoretical framework implies, when the industry's ROA is trending downward, the continuation value for the incumbent to stay with the firm is low - the prospects of the industry are not good and the value of future payments to be received from the firm is lower. Another explanation, outside the competitive assignment model, is that leaving when the industry is going through bad times allows the CEO to not be inferred as being of as low a type if he left while the industry was experiencing a boom. Similarly, the continuation value for the incumbent is higher when the firm is doing well relative to the industry, in terms of ROA or stock returns.

We find that if the firm's stock return or employment growth relative to the industry are higher, the odds of the CEO retiring decrease. Since CEO compensation increases with firm stock performance and also with firm size, and some managers may also enjoy empire building, we interpret these results as indicating that if the value of staying in the match is higher, the CEO is less likely to retire.

Finally, the results in Table 2 show that CEOs younger than 65 years are significantly less likely to either retire or leave for unknown reasons, relative to older individuals. At 
the same time, the likelihood of being fired relative to continuing as a CEO does not depend on the executive's age.

\subsection{Match formation}

In this section we test the second hypothesis, (H2), which states that when industry conditions deteriorate, replacement CEOs are more likely to have skills different from those of departing CEOs.

We first document general patterns in the types of replacements hired during 19932005. The frequency of replacements by company insiders has decreased over time from $70 \%$ in 1993 to $59.5 \%$ in 2005 , supporting the argument that general management skills are now relatively more valuable than firm-specific skills compared to earlier periods (Frydman (2005)). Also, the frequency of replacements by individuals coming from privatelyheld firms has increased over time, from $1.75 \%$ in 1993 to $5.40 \%$ in 2005 .

In line with our hypothesis that matches are formed based on the fit of the CEO's skill set with the company's needs, we find evidence suggesting that companies going through difficult times, either because of idiosyncratic reasons or because of industry conditions, are more likely to hire replacement CEOs with a different background than the incumbent executive.

We find that company outsiders are more likely to be brought in after a firing or after a voluntary departure of the incumbent, which tend to occur when the firm or the industry experience difficult times, than after a retirement. Moreover, most of these outsiders are from a different industry according to the Fama French 48 industry classification system. ${ }^{28}$

Figure 7 indicates the types of replacement CEOs hired after each type of departure and suggest that the type of replacement CEO hired depends on the reason for the departure of the prior CEO. Replacements by company insiders are significantly more likely if the prior CEO left because of retirement than if he possibly quit or was fired. In the case of retirements, only $20.3 \%$ of the new CEOs are from outside the company: $4.2 \%$ are from the same industry, $11.6 \%$ are from a different industry, and $4.5 \%$ come from a non-publicly traded company. In the case of possible quits, $28.3 \%$ of the new CEOs are from outside the company: $5.5 \%$ are from the same industry, $15.7 \%$ are from a different industry, and $7.1 \%$ are from a non-publicly traded company. After firings,

\footnotetext{
${ }^{28}$ The same is true if we use the 2-digit SIC industry classification code, which yields 61 different industries in our sample.
} 
$37.8 \%$ of replacements are company outsiders: $9.1 \%$ are from the same industry, $21.2 \%$ from another industry, and $7.5 \%$ from a non-publicly traded company.

We check the robustness of these results by estimating a multinomial logit model of the relative likelihood of various types of replacement CEOs as function of the prior CEO's departure reason, and industry fixed-effects. The results are shown in Table 3 and confirm the unconditional findings.

To get more direct evidence that industry conditions matter for the type of replacement CEO hired, we split the firm-year observations into those belonging to industries with below-average and above-average ROA during 1993-2005. To keep the analysis simple, we bundle together all three types of replacement CEOs from outside the company, and refer to these individuals as "outsiders". Replacement CEOs hired from within the firm are referred to as "insiders".

Figure 8 shows that the number and frequency of turnover events for low and high ROA industries, and for each departure reason and replacement type. In low ROA industries there are more instances of firings and unclassified departures (possible quits) than in high ROA industries, and in such instances it is more likely that an outsider will be brought in, relative to similar instances in high ROA industries. For instance, in high ROA industries there were 122 instances were the incumbent was fired and in $36 \%$ of these cases, he was replaced by an outsider. In low ROA industries there were 185 firings, and $39 \%$ of these instances led to an outside hire. Similarly, in high ROA industries there were 518 instances of possible quits, and $25 \%$ of these were followed by an outside hire. In low ROA industries, there were 619 instances of possible quits, and in $32 \%$ of these cases an outsider was brought in.

We interpret these patterns as evidence that the more likely it is that the incumbent CEO-firm match is suboptimal, the more likely it is for the firm to bring in a replacement CEO with a different background and expertise than a company insider. This evidence is consistent with the finding documented by Allgood and Farrell (2003) that best firmCEO matches tend to occur when inside CEOs follow previous CEOs who quit, and when outside CEOs follow previous CEOs who are dismissed.

To see whether these univariate results are robust, we estimate a multivariate probit model for the likelihood that the replacement CEO is an outsider. We allow stock market and real variables that describe firm and industry conditions to influence this likelihood, as we did in our analysis of types of CEO departures in Table 2. The results of this probit model are shown in Table 4 . 
Since we condition on there being turnover and then inquire what type of CEO is hired, our analysis is different from that in Parrino (1997), where firm-specific performance is used to predict what type of CEO is in place, and "no turnover" (i.e. the incumbent is still CEO) is one of the possible outcomes. The results there indicate that the likelihood of outside succession, relative to there being no turnover, is negatively related to industry-adjusted stock returns and ROA. In other words, replacing a CEO, and doing so with an outsider, happens when the firm is underperforming the industry. Our evidence complements the result in Parrino (1997) and also shows that industry conditions matter for the type of CEO hired. We argue that this is because of the effect of such conditions on the desired management style or skill set.

The results in Table 4 show that the probability of a replacement by an outsider relative to an insider is higher when the firm's industry-adjusted stock return and ROA are lower, a result very much in the spirit of that of Parrino (1997). We also find that a succession by a company outsider is more likely relative to an inside succession when the industry ROA is lower, and if the industry has experienced a lower growth in employment. This pattern holds whether we measure employment using CRSP/Compustat figures that refer to public companies only, or BEA figures that capture the overall employment in private and public companies (reported using the NAIC industry classification). Therefore, replacements by outsiders seem to be particularly common after poor firm and industry performance, that is, at times when continuing the same strategy as before may not be beneficial.

Figure 9 shows the dynamics of firm ROA performance relative to the industry for all CEO departure reasons and replacement types, to illustrate that these different types of turnover events happen to firms in different circumstances. Independent of the type of CEO departure, the firm's ROA relative to that of the industry is lower prior to the turnover event in cases where the new $\mathrm{CEO}$ is a company outsider, relative to those where there is no replacement or the new CEO is a company insider. The under-performance of firms under incumbent CEOs who are eventually replaced by outsiders is greatest in instances when the incumbent is fired, and smallest in instances when the incumbent's departure is due to retirement. Overall, it appears that outside CEOs are brought in to replace incumbents who are no longer a good match for the firm. 


\subsection{Compensation and CEO skills}

The third main hypothesis we test, (H3), states that the pay of CEOs reflects the market price of their skill bundles. As the model suggests, the pay offered to the new CEO must compensate him for his forgone outside option. For an individual to decide to take the CEO job at a firm that is performing poorly, or is in an industry going through a downturn, he must receive higher compensation than the CEO of a less distressed firm, as suggested by the example in section 2.1. We find evidence consistent with these arguments, as shown in Figures 10 to 14 and the regression model in Table 5.

When an outsider is brought in, irrespective of the reason for departure of the prior CEO, his total pay is higher than that of an insider replacement, a continuing CEO or the prior CEO (Figure 10). Therefore, since pay does not decrease in the event of a replacement by an outsider, such events must occur because the outsider's ability or quality of match is higher than that of the incumbent, and because the outsider has more general human capital than the incumbent CEO that can be deployed in other firms or industries.

The sizable increase in pay of the outsider relative to that of an insider replacement, a continuing $\mathrm{CEO}$ or the prior CEO is driven mostly by the value of the option grants given to the new CEO who is brought from outside the company (Figure 11) and less so through bonuses (Figure 13) or other types of pay that exclude salary, bonus or option grants (Figure 14). Salaries of outsider replacement CEOs are actually lower than those received by CEOs in these three comparison categories (Figure 12). The highest pay is received by new CEOs who come in after the prior CEO was fired, with outsiders getting paid more than insiders. New CEOs from inside the company are paid a similar amount as continuing CEOs at companies that do not experience turnover.

The regression models in Table 5 yield the same results as univariate findings in Figures 10 through 14. Controlling for industry and year fixed-effects, as well as firm market value, we find that the total pay of a new CEO is lowest if he is an insider replacing a retired incumbent ( $\$ 0.45$ million less than the pay of a continuing CEO), and highest if he is a company outsider replacing a fired incumbent (\$2.5 million more than the pay of a continuing CEO). Irrespective of the departure reason (retirement, possible quit, or forced out), the replacement CEO will earn total compensation equal or lower than continuing CEOs if he is a company insider, but higher than continuing CEOs if he is a company outsider. 


\section{Conclusion}

We consider the link between industry conditions and the CEO labor market in the context of a competitive assignment model where both the CEO and firm optimize over the relative value of preserving the match versus pursuing their outside option. In contrast to a principal-agent framework where only relative performance affects CEO turnover, in a matching environment both firm and CEO characteristics as well as broader industry conditions naturally drive turnover events. Although the competitive assignment model has been used by several authors recently to explain empirical facts about CEO pay, we are the first to show that such a model can also be used to successfully understand the dynamics of CEO turnover.

We find empirical support for these ideas using a large dataset we construct describing turnover events during the period 1992-2006. We collect information regarding both the reason for the incumbent CEO's departure and the identity and background of the new CEO. This information allows us to ascertain with greater precision the reason behind the turnover event. We study the effect of firm and industry conditions on the likelihood of turnovers categorized as forced departures, quits or retirements. We similarly document the determinants of the choice of whether the replacement CEO will be a firm insider or outsider, and show that type and pay of the new CEO is related to the reason behind the incumbent's replacement. Our empirical findings generally match our theoretical predictions and illustrate that a competitive assignment model can explain the patterns in observed managerial turnover across industries and over time. 


\section{References}

Allgood, S. and K. A. Farrell (2003). The match between CEO and firm. Journal of Business 76(2), 317-341.

Barro, J. R. and R. J. Barro (1990, October). Pay, performance and turnover of bank CEOs. Journal of Labor Economics 8(4), 448-481.

Bebchuk, L. and J. Fried (2004). Pay without Performance. Cambridge, MA and London, England: Harvard University Press.

Bertrand, M. and A. Schoar (2003, November). Managing with style: The effect of managers on firm policies. Quarterly Journal of Economics 118(4), 1169:1208.

DeMarzo, P., M. Fishman, Z. He, and N. Wang (2009). Dynamic agency and the q theory of investment. Working paper.

DeMarzo, P. M. and M. J. Fishman (2007a, January). Agency and optimal investment dynamics. Review of Financial Studies 20, 151-188.

DeMarzo, P. M. and M. J. Fishman (2007b, November). Optimal long-term financial contracting. Review of Financial Studies 20, 2079-2128.

Dicks, D. (2009). Executive Compensation, Incentives, and the Role for Corporate Governance Regulation. Working paper, UNC.

Edmans, A. and X. Gabaix (2009). Is CEO pay really inefficient? A survey of new optimal contracting theories. European Financial Management 15(3), 486-496.

Eisfeldt, A. and A. Rampini (2008). Managerial incentives, capital reallocation, and the business cycle. Journal of Financial Economics, 177-199.

Frydman, C. (2005). Rising Through the Ranks. The Evolution of the Market for Corporate Executives, 1936-2003. Harvard University, Working Paper.

Gabaix, X. and A. Landier (2008). Why Has CEO Pay Increased So Much? Quarterly Journal of Economics 123(1), 49-100.

Giannetti, M. (2009). Serial CEO incentives and the structure of managerial contracts. Working paper.

Gibbons, R. and K. J. Murphy (1990, February). Relative performance evaluation for Chief Executive Officers. Industrial and Labor Relations Review 43(3. Special issue: Do Compensation Policies Matter?), 30S-51S. 
He, Z. (2007). Dynamic compensation contracts with private savings. Working paper. He, Z. (2009). A model of dynamic compensation and capital structure. Working paper. Holmstrom, B. (1982). in Essays in Economics and Management in Honor of Lars Wahlbeck, Chapter Mangerial incentive problems: A dynamic perspective. Helsinki, Finland. Republished in the Review of Economic Studies, 1999, 66, 169-182.

Huson, M. R., P. H. Malatesta, and R. Parrino (2004). Managerial succession and firm performance. Journal of Financial Economics, 237-275.

Huson, M. R., R. Parrino, and L. Starks (2001, December). Internal monitoring mechanisms and CEO turnover: A long-term perspective. Journal of Finance 56(6).

Jenter, D. and F. Kanaan (2006, February). CEO turnover and relative performance evaluation. Working paper, MIT.

Kaplan, S. and B. A. Minton (2006, August). How has CEO turnover changed? Increasingly performance sensitive boards and increasingly uneasy CEOs. NBER Working paper 12465.

Lancaster, K. J. (1966). A New Approach to Consumer Theory. Journal of Political Economy 74, 132-156.

Lucas, Robert E., J. (1978). On the Size Distribution of Business Firms. Bell Journal of Economics, 508-523.

Lustig, H., C. Syverson, and S. Van Nieuwerburgh (2009). Technological change and the growing inequality in managerial compensation. NBER Working Paper 14661.

Murphy, K. J. (1999). Executive Compensation. Handbook of Labor Economics 3.

Murphy, K. J. and J. Zabojnik (2004). CEO Pay and Appointments: A Market-based explanation for recent trends. American Economic Review Papers and Proceedings 94(2), 192-196.

Murphy, K. J. and J. Zabojnik (2007, April). Managerial capital and the market for CEOs. Working paper.

Parrino, R. (1997). CEO turnover and outside succession. Journal of Financial Economics 46, 165-197.

Peters, F. S. and A. F. Wagner (2007, December). The executive turnover risk premium. Working paper. 
Rosen, S. (1974). Hedonic prices and implicit markets. Journal of Political Economy 82, 34-35.

Rosen, S. (1981). The economics of superstars. American Economic Review 71, 845858.

Sannikov, Y. (2008, July). A continuous-time version of the principal-agent problem. Review of Economic Studies $75(3), 957-984$.

Sattinger, M. (1979). Differential rents and the distribution of earnings. Oxford Economics Papers 31(1), 60-71.

Sattinger, M. (1993). Assignment Models of the Distribution of Earnings. Journal of Economic Literature 31, 831-880.

Tervio, M. (2008). The Difference That CEOs Make: An Assignment Model Approach. American Economic Review 98(3), 642-668.

Warner, J., R. Watts, and K. Wruck (1988). Stock prices and top management changes. Journal of Financial Economics 20, 461-492. 


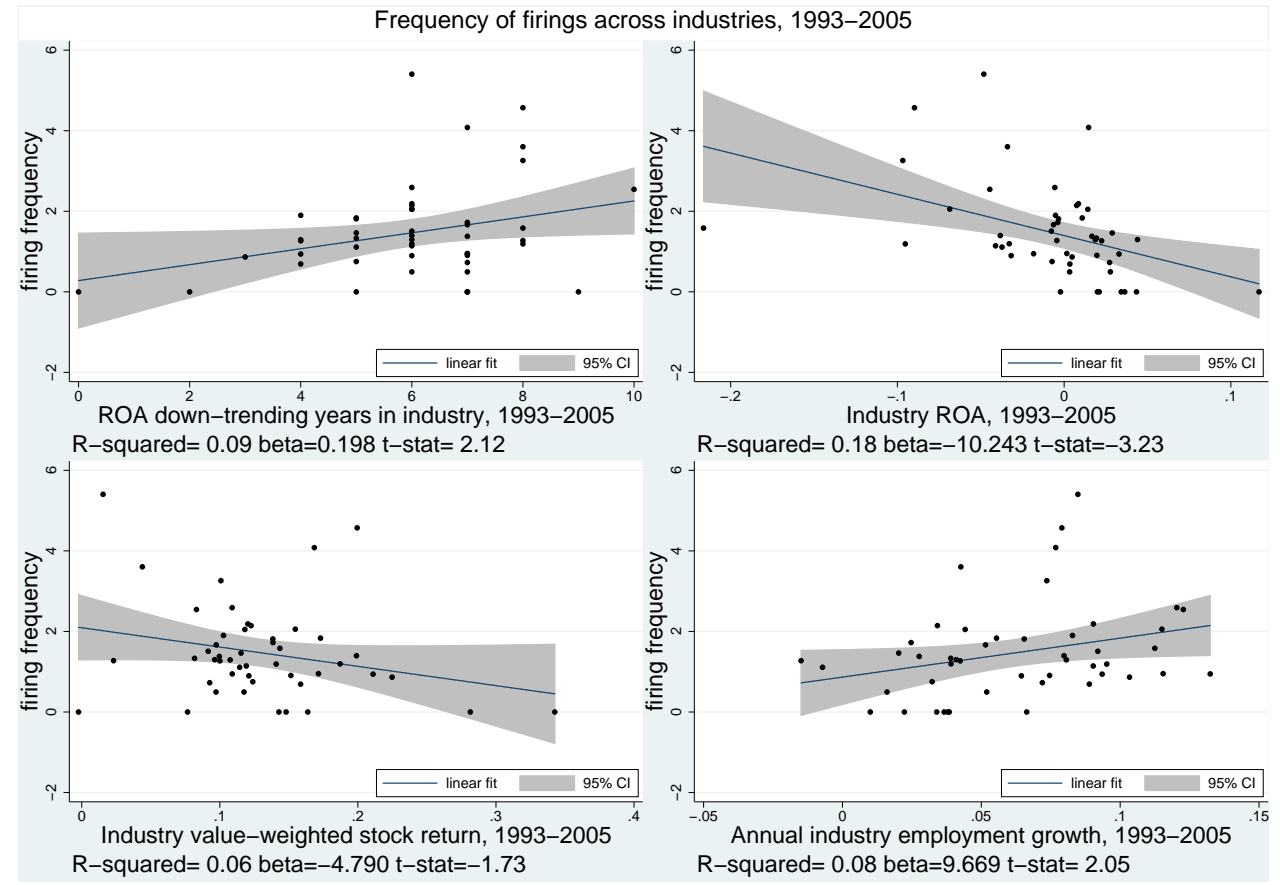

Figure 3: Frequency of firings and industry conditions during 1993-2005.

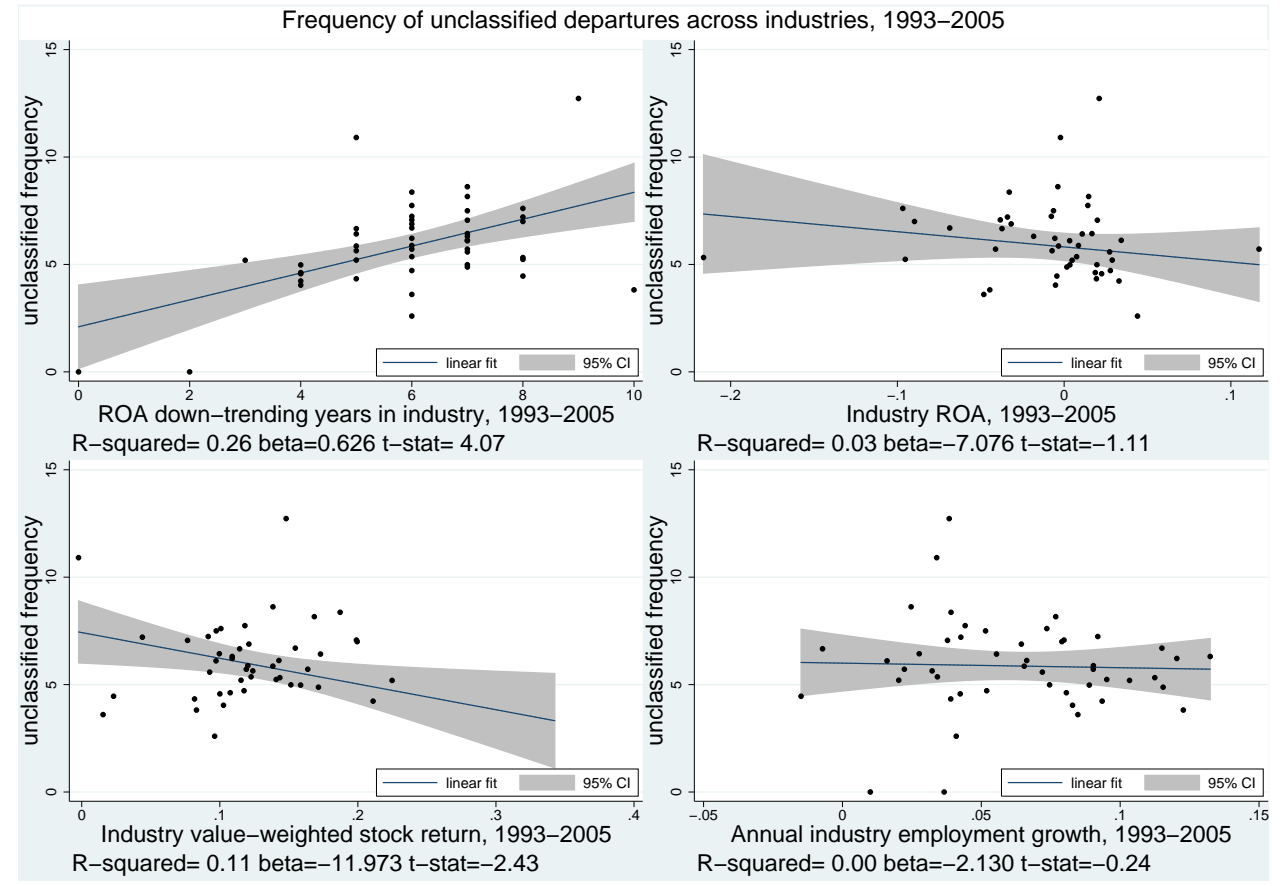

Figure 4: Frequency of unclassified departures and industry conditions during 1993-2005. 

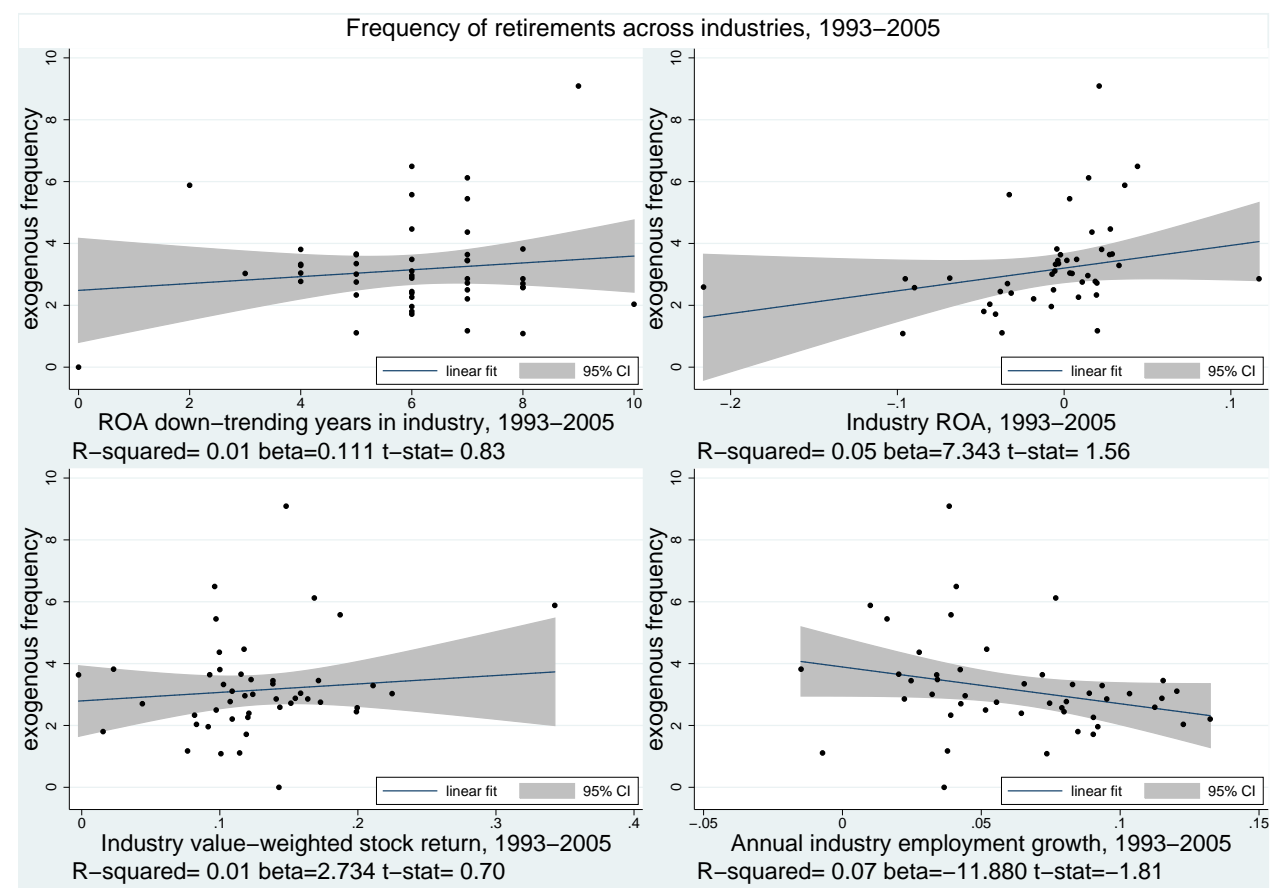

Figure 5: Frequency of retirements and industry conditions during 1993-2005. 


\section{Frequency of turnover across industries}

by quartile of industry ROA

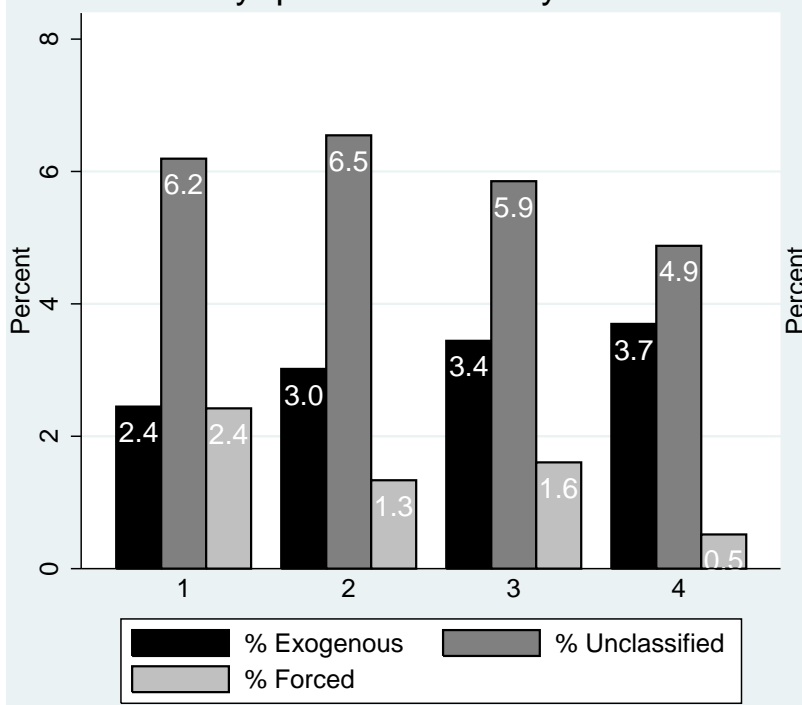

by quartile of industry stock returns

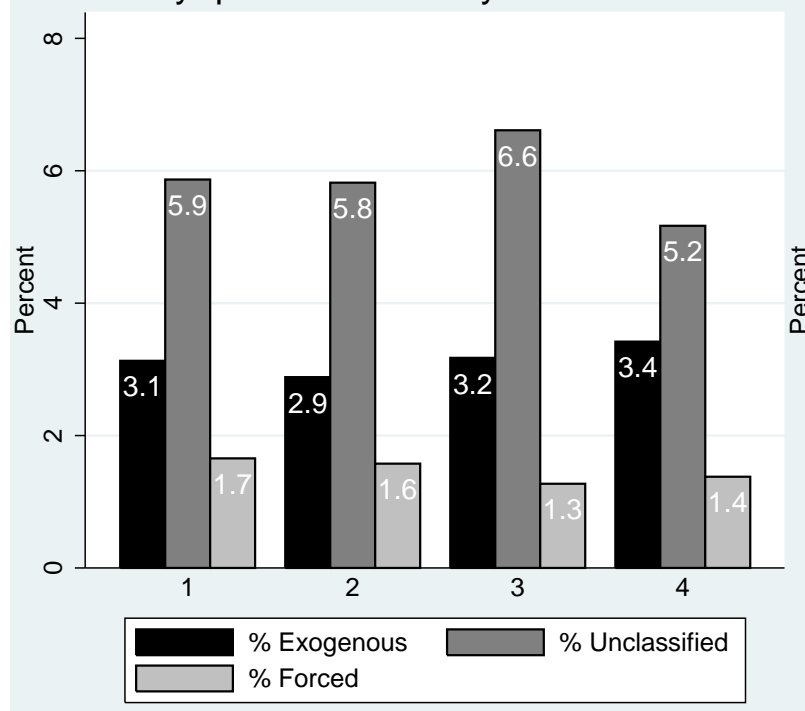

by quartile of industry ROA down-trending years

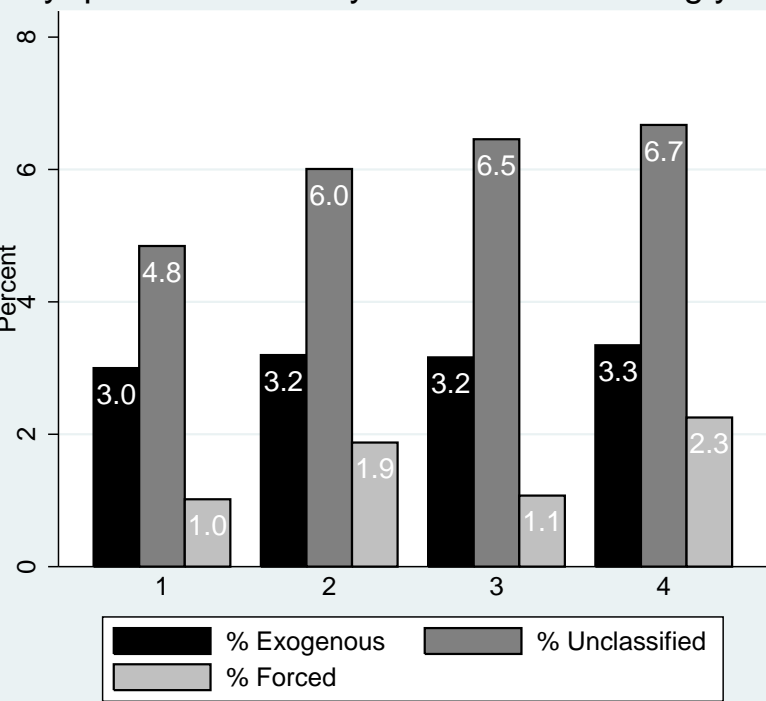

by quartile of industry employment growth

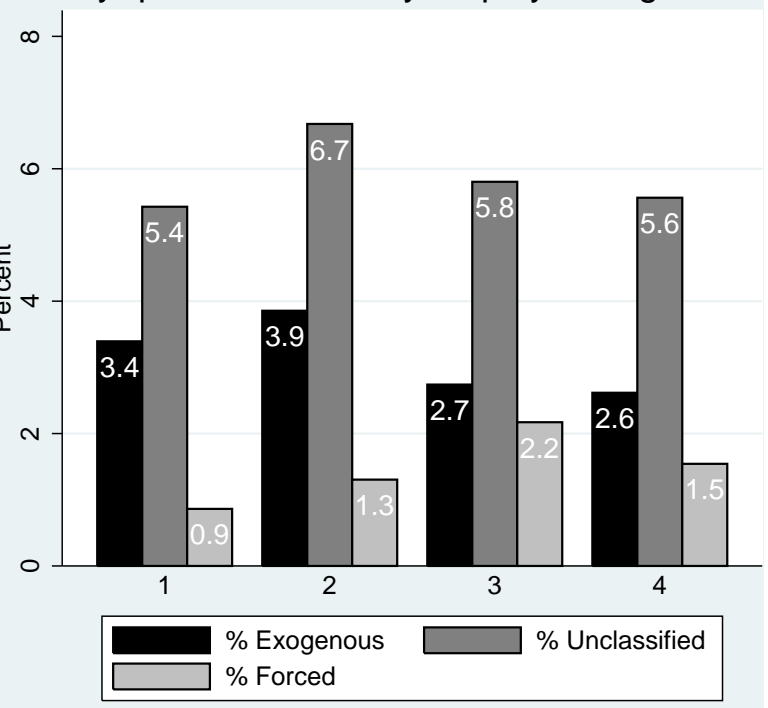

Figure 6: Frequency of turnover types as a function of industry conditions, 1993-2005. 


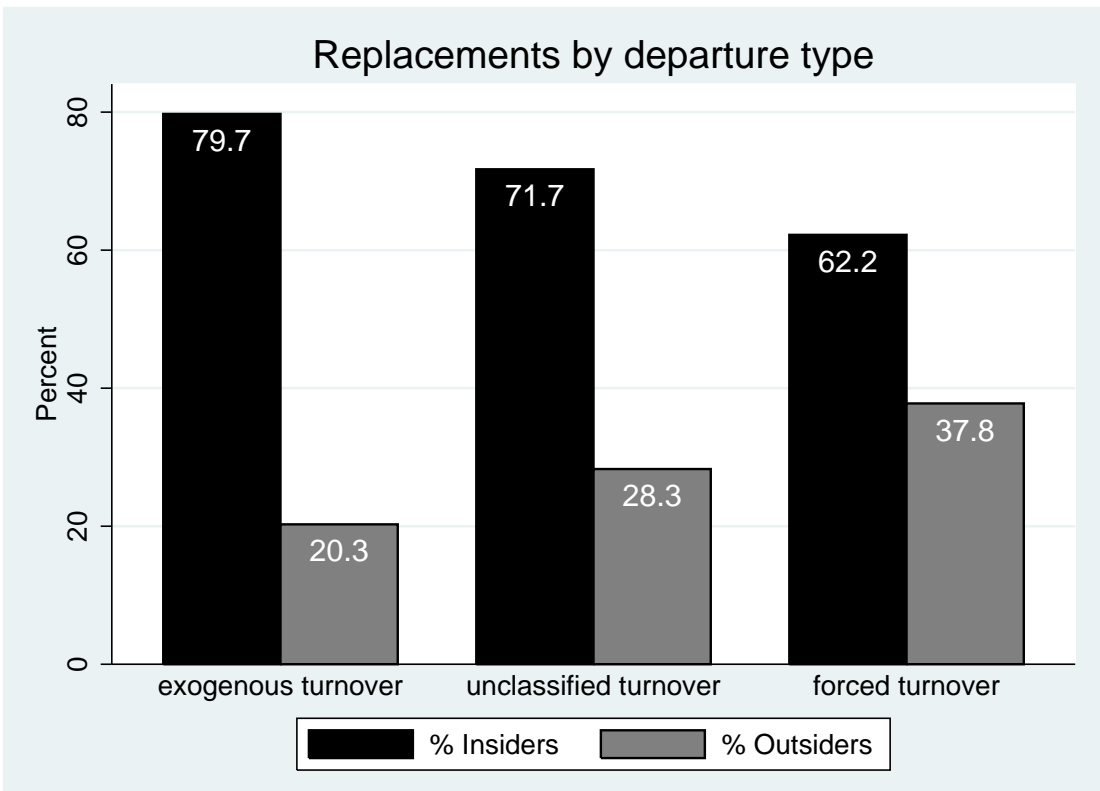

Replacements by departure type

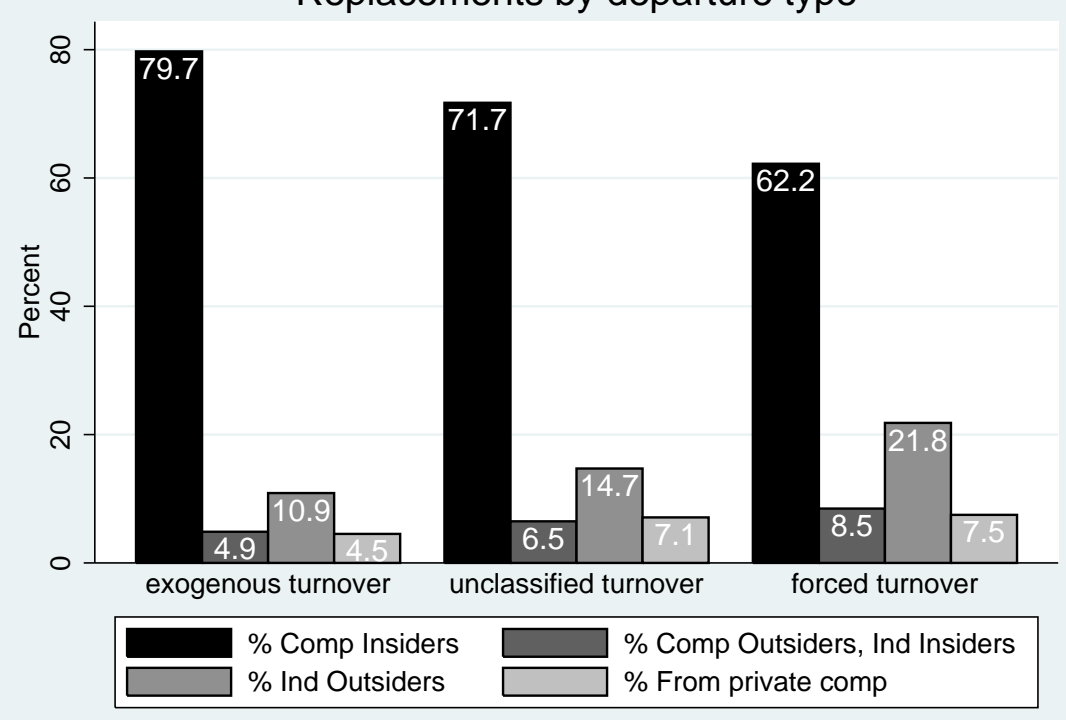

Figure 7: Replacement types and departure reasons. 


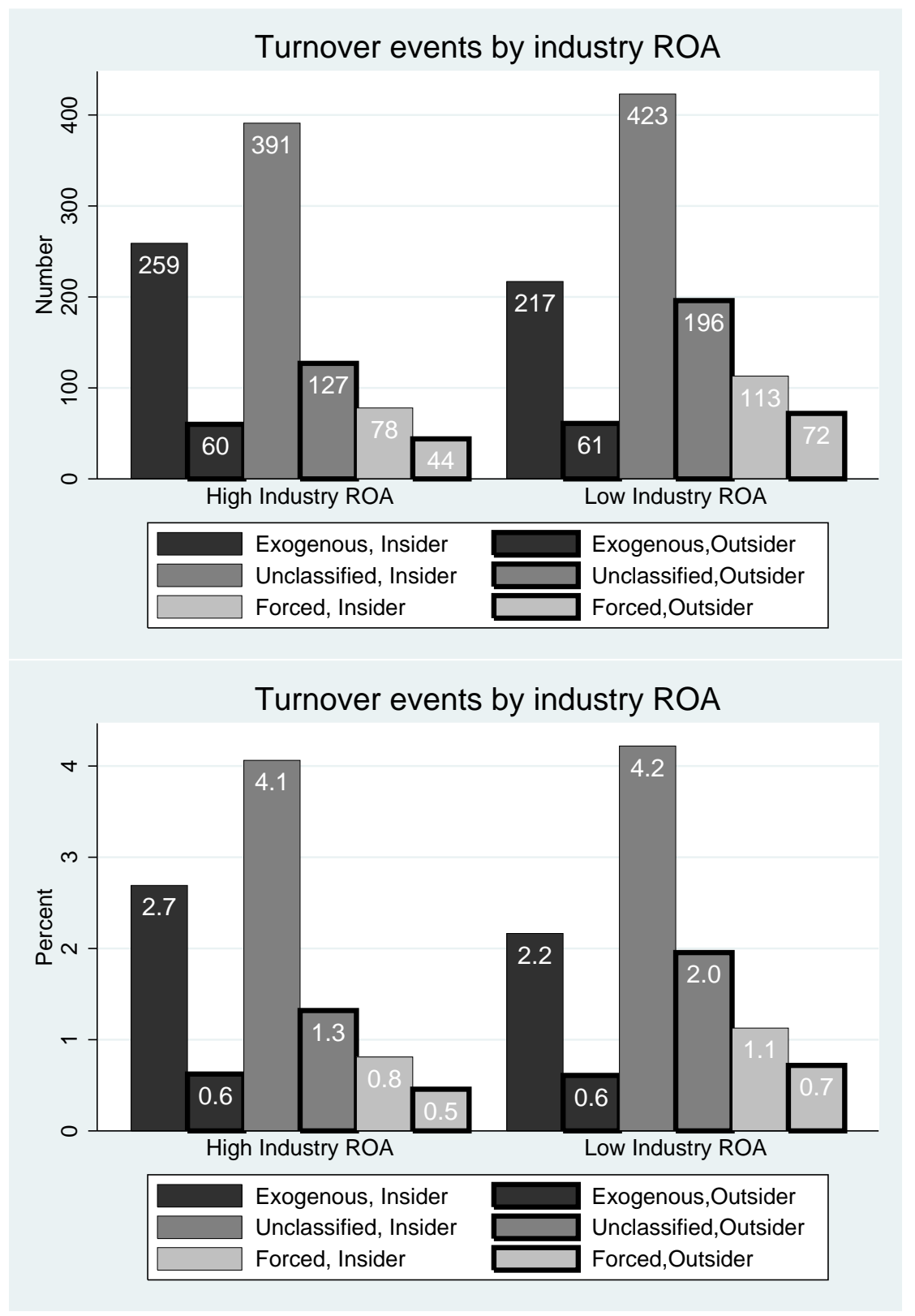

Figure 8: Turnover events (number and frequency) by industry ROA. 


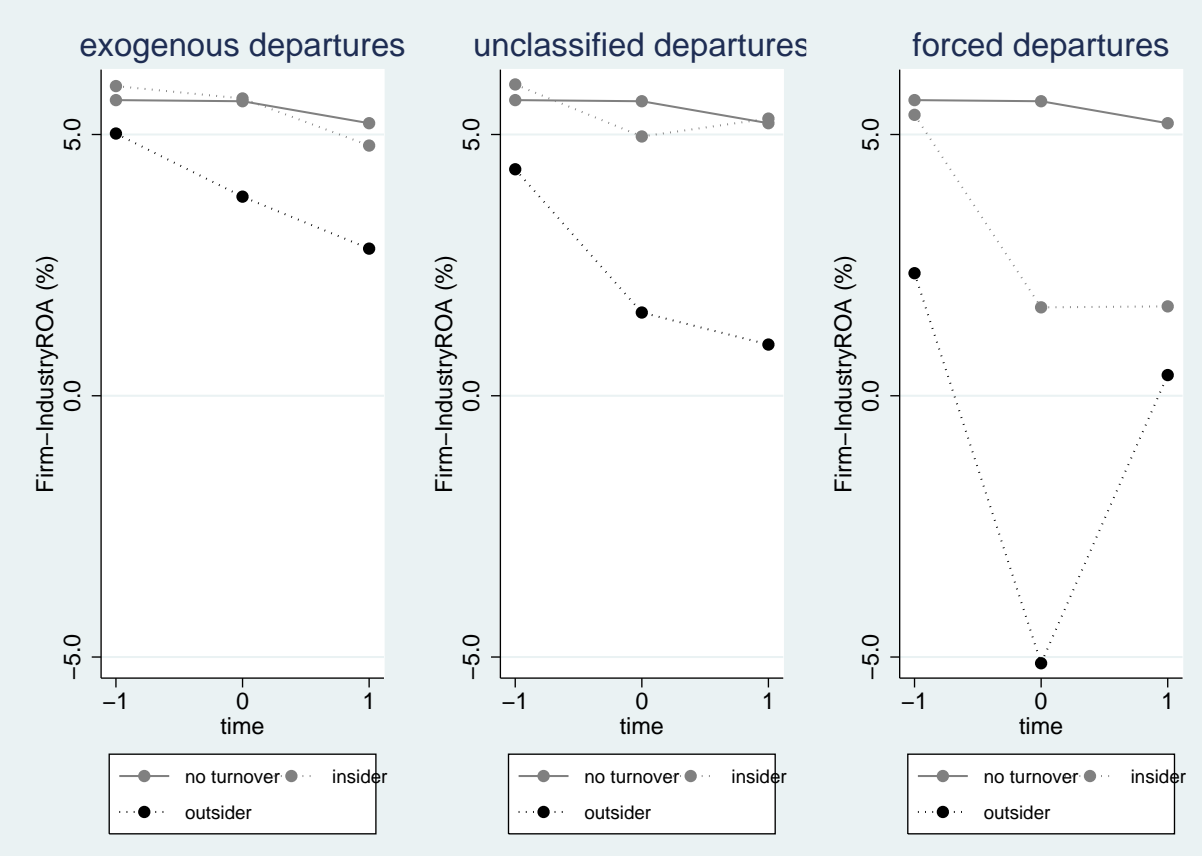

Figure 9: Firm relative to industry ROA dynamics around turnover year (time 0).

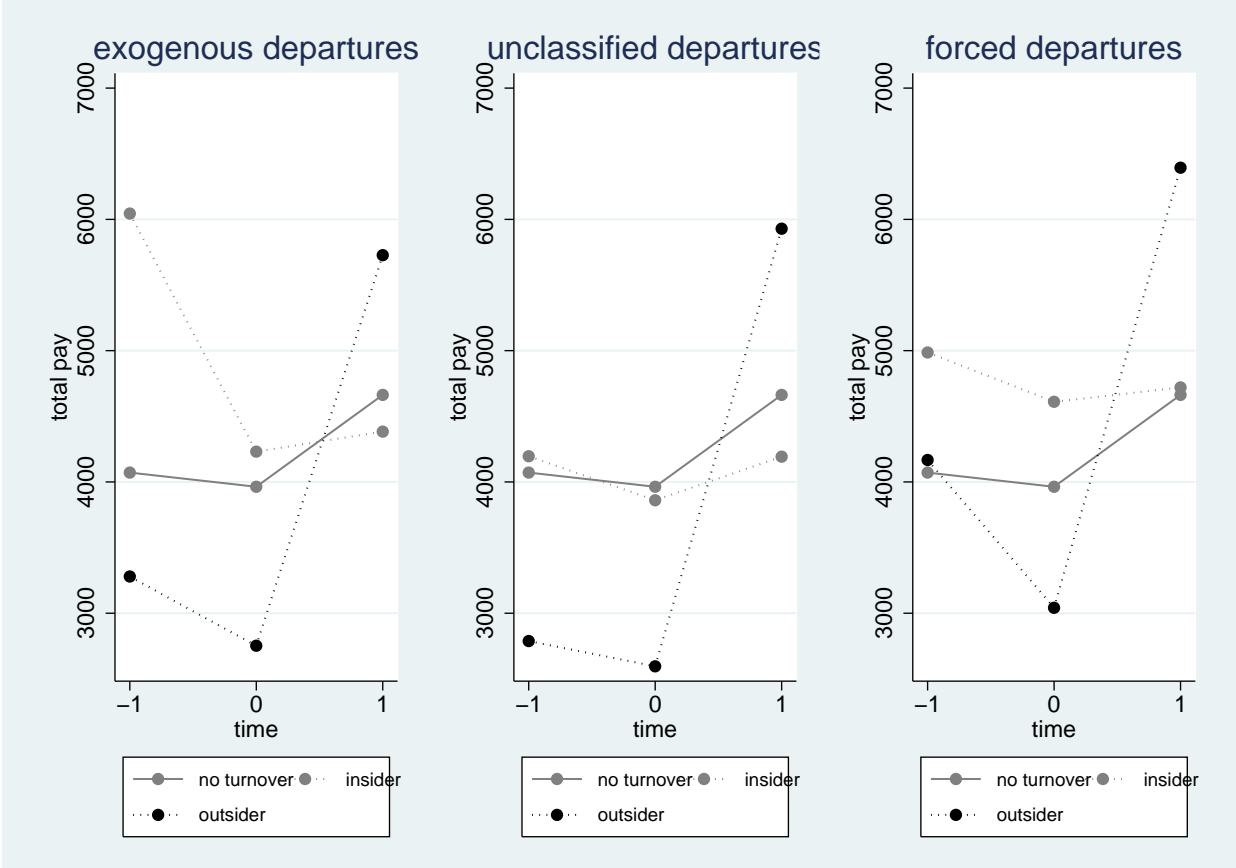

Figure 10: Total pay dynamics around turnover year (time 0). 


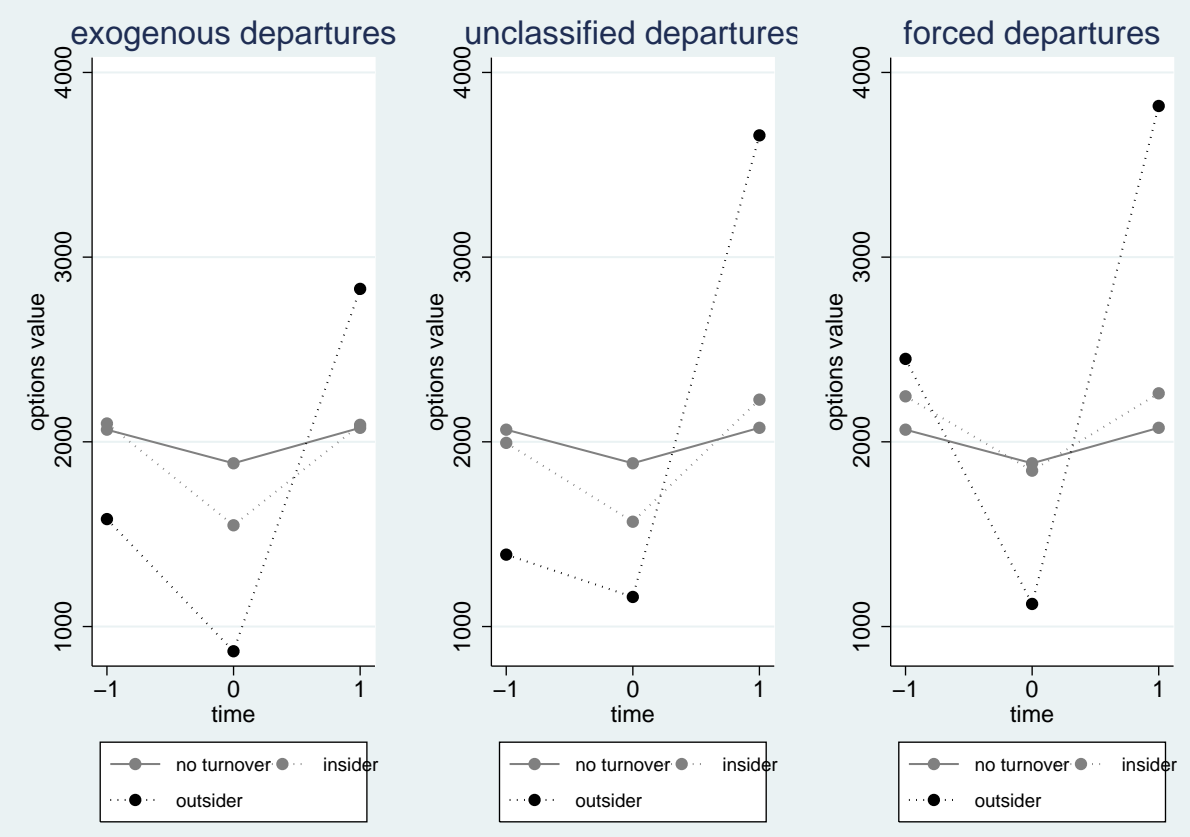

Figure 11: Options value dynamics around turnover year (time 0).

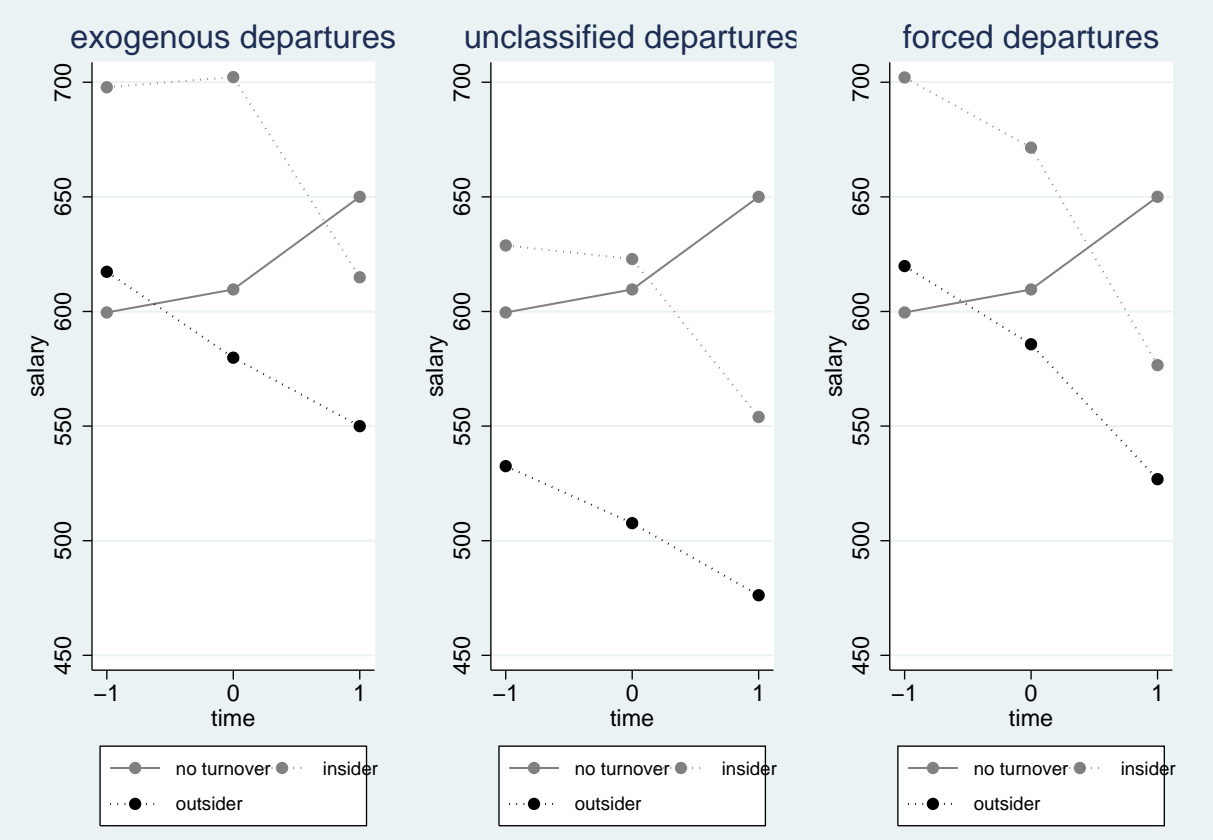

Figure 12: Salary dynamics around turnover year (time 0). 

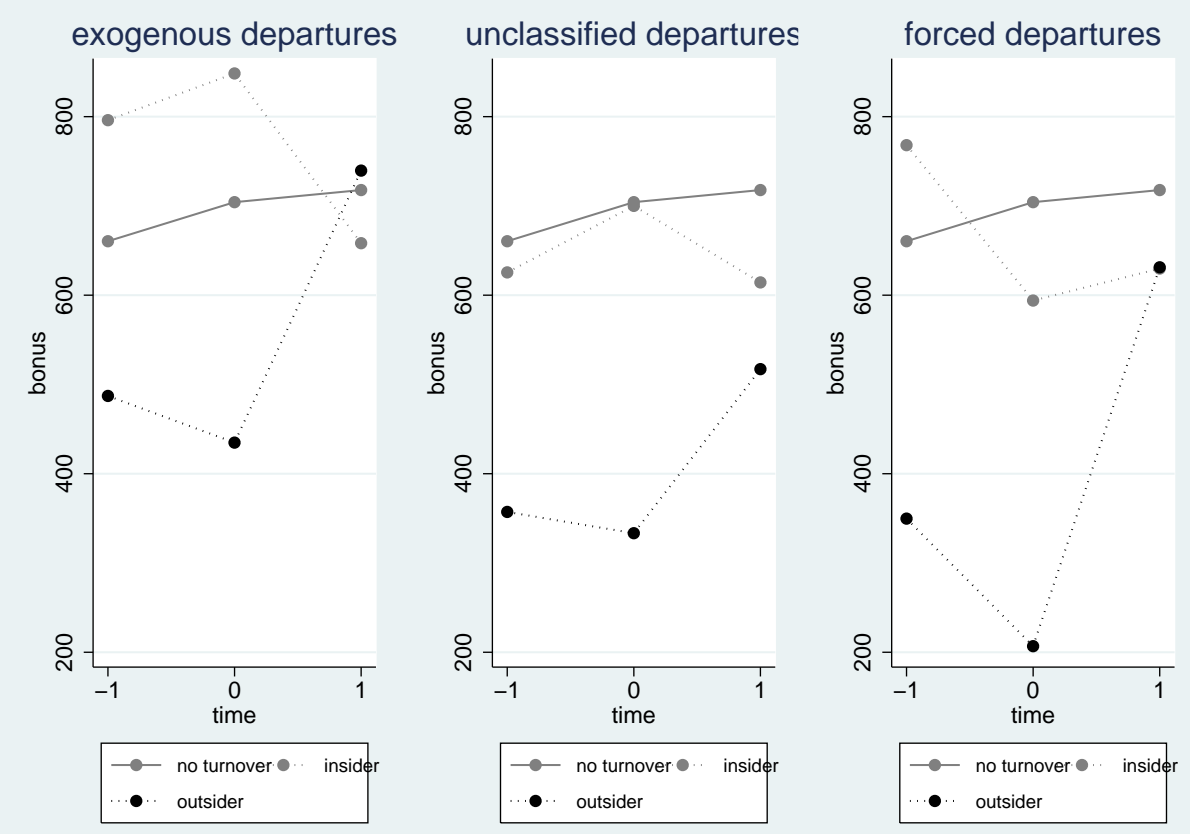

Figure 13: Bonus dynamics around turnover year (time 0).
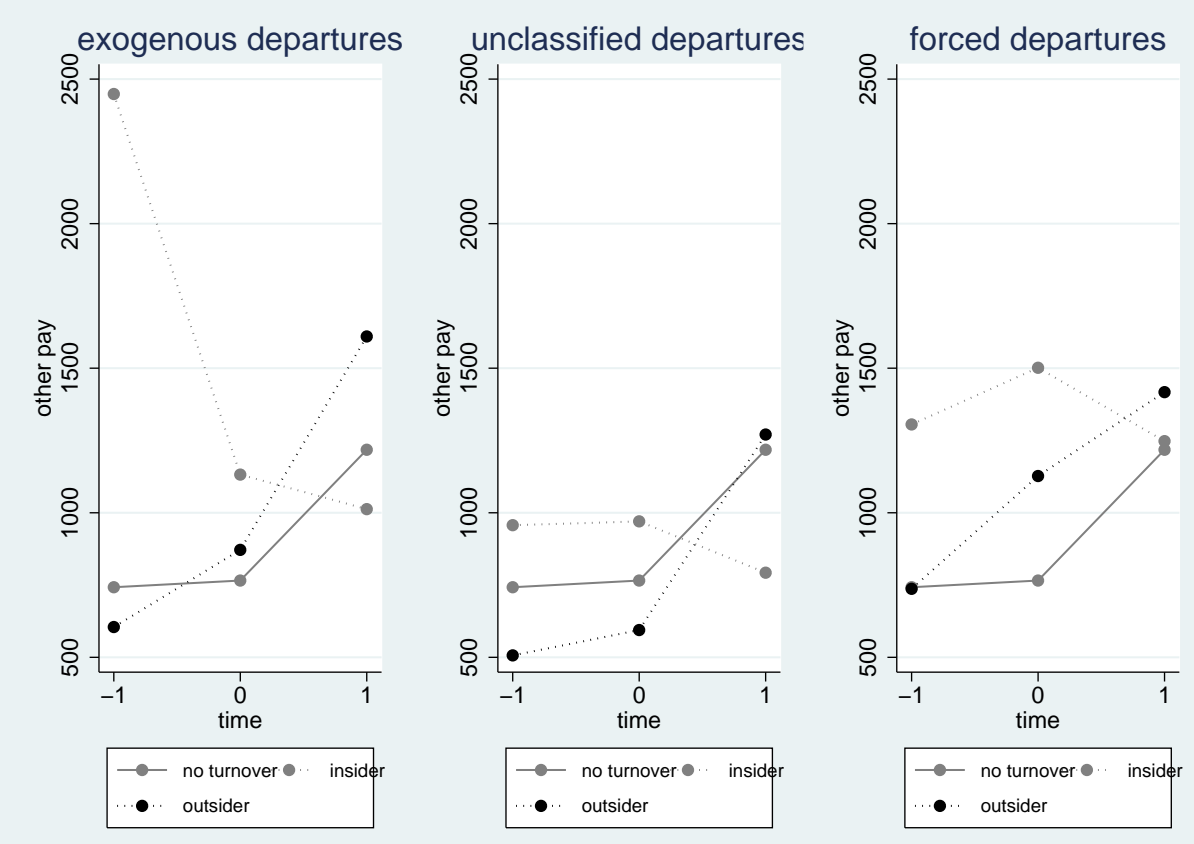

Figure 14: Other pay dynamics around turnover year (time 0). 


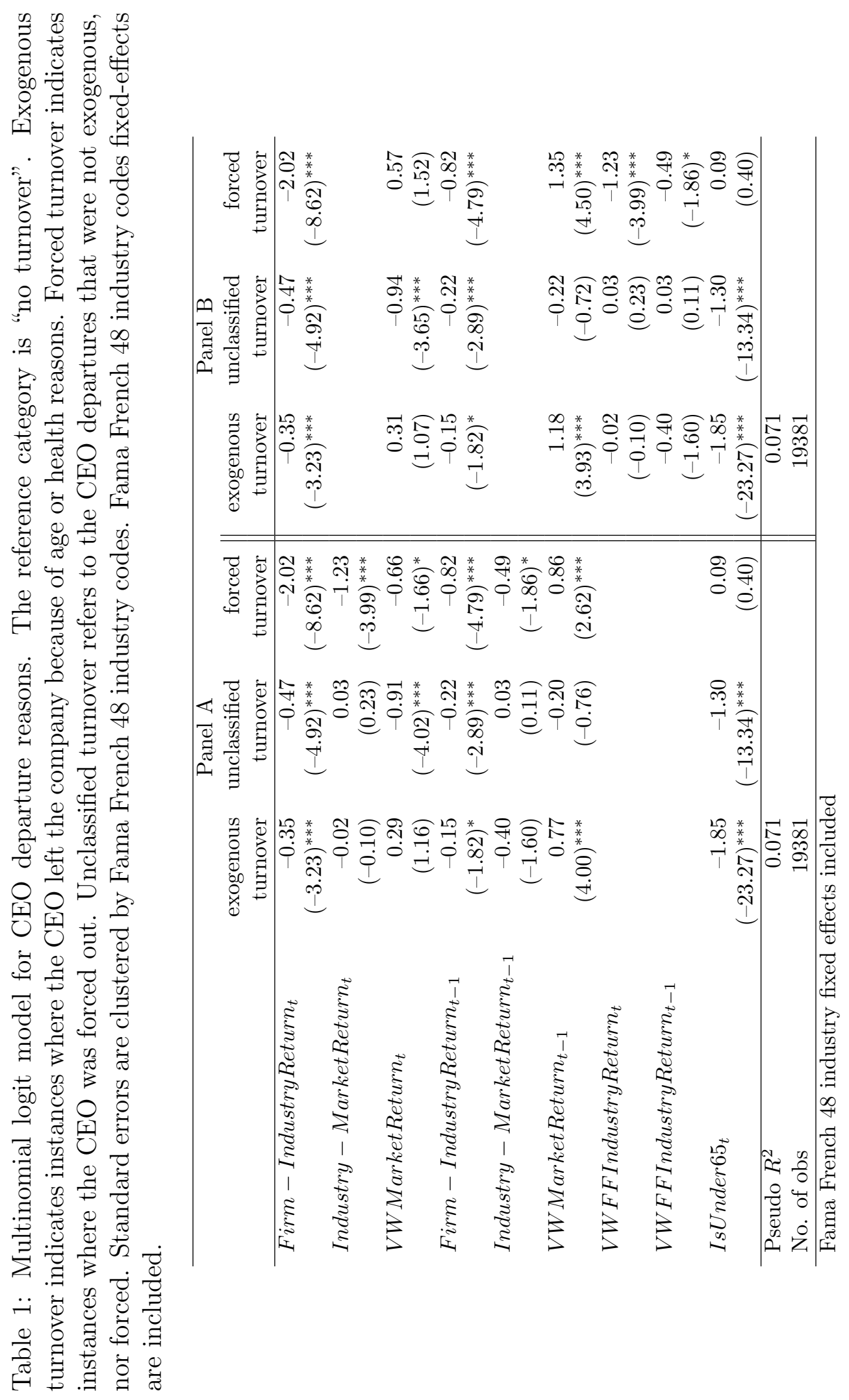




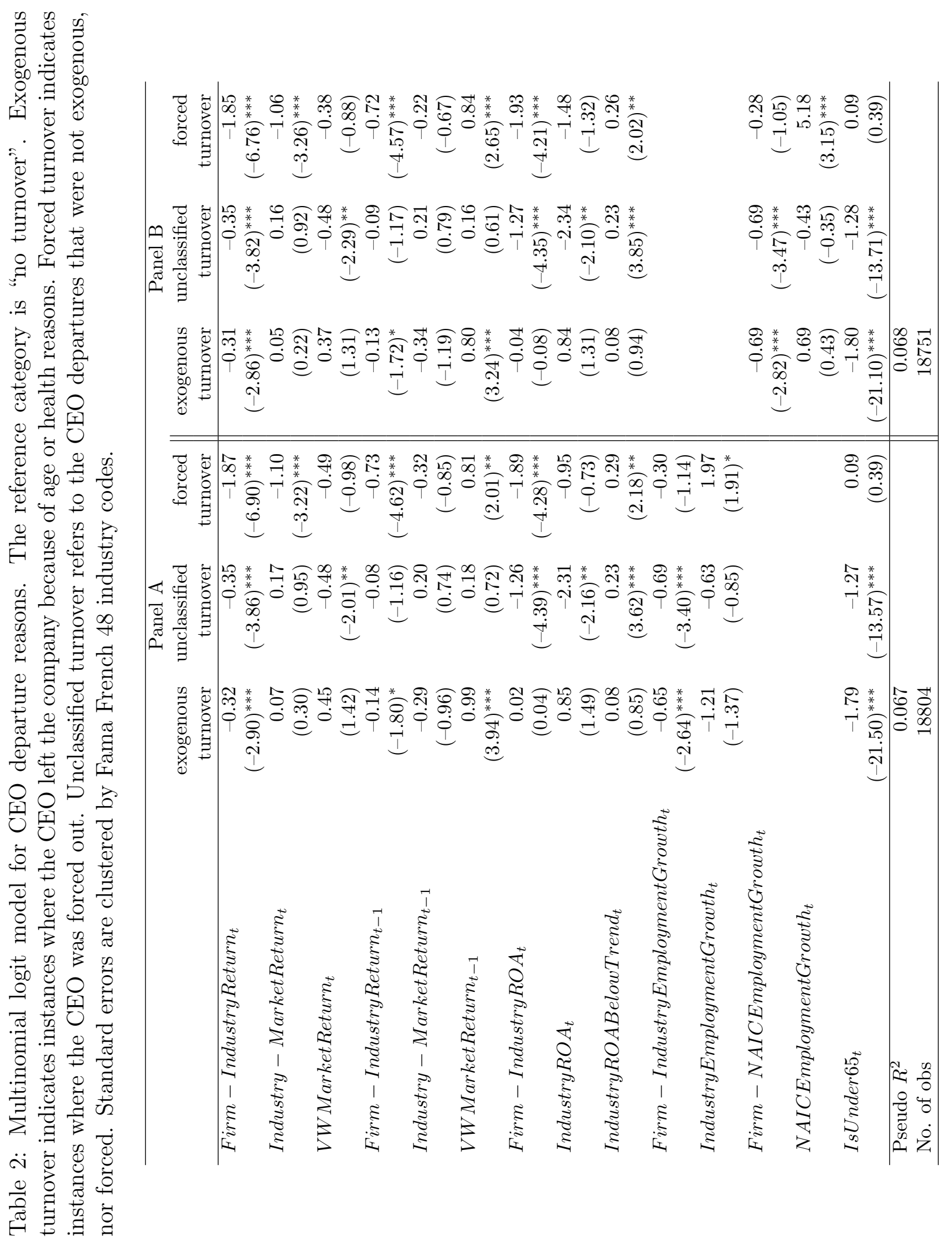


Table 3: Multinomial logit model for CEO replacement types. The reference replacement category is "company insider". Fama French 48 industry code fixed effects are included. Standard errors clustered by Fama French 48 industry code.

\begin{tabular}{lrrr}
\hline & $\begin{array}{c}\text { company outsider, } \\
\text { industry insider }\end{array}$ & $\begin{array}{r}\text { industry outsider } \\
\text { from public co. }\end{array}$ & from private firms \\
\hline UnclassifiedDeparture $_{t}$ & 0.37 & 0.32 & 0.34 \\
& $(1.71)^{*}$ & $(1.83)^{*}$ & $(1.35)$ \\
ForcedDeparture $_{t}$ & 0.79 & 0.89 & 0.50 \\
& $(2.70)^{* * *}$ & $(4.43)^{* * *}$ & \\
\hline Pseudo $R^{2}$ & 0.073 & & \\
No. of obs & 2125 & \\
\hline Fama French 48 industry fixed-effects included
\end{tabular}


Table 4: Probit models for the likelihood that the replacement CEO is a company outsider. Reference category is "company insider". Standard errors clustered by Fama French 48 industry code.

\begin{tabular}{|c|c|c|}
\hline \multirow[t]{2}{*}{ Dependent variable } & \multicolumn{2}{|c|}{ Replacement is company outsider } \\
\hline & Panel A & Panel B \\
\hline \multirow[t]{2}{*}{ Firm - IndustryReturn $_{t}$} & -0.32 & -0.33 \\
\hline & $(-4.73)^{* * *}$ & $(-4.68)^{* * *}$ \\
\hline \multirow{2}{*}{ Industry - MarketReturn $_{t}$} & -0.01 & -0.02 \\
\hline & $(-0.07)$ & $(-0.09)$ \\
\hline \multirow{2}{*}{$V W$ MarketReturn $_{t}$} & 0.38 & 0.31 \\
\hline & $(1.89)^{*}$ & $(1.65)^{*}$ \\
\hline \multirow{2}{*}{ Firm - IndustryReturn $n_{t-1}$} & -0.04 & -0.04 \\
\hline & $(-0.67)$ & $(-0.66)$ \\
\hline \multirow{2}{*}{ Industry - MarketReturn $n_{t-1}$} & 0.20 & 0.12 \\
\hline & $(1.58)$ & $(0.97)$ \\
\hline \multirow[t]{2}{*}{$V W$ MarketReturn $n_{t-1}$} & 0.04 & 0.04 \\
\hline & $(0.21)$ & $(0.19)$ \\
\hline \multirow[t]{2}{*}{ Firm - IndustryROA $A_{t}$} & -1.22 & -1.21 \\
\hline & $(-5.12)^{* * *}$ & $(-5.08)^{* * *}$ \\
\hline \multirow{2}{*}{ IndustryROA $A_{t}$} & -2.52 & -2.14 \\
\hline & $(-3.79)^{* * *}$ & $(-2.88)^{* * *}$ \\
\hline \multirow[t]{2}{*}{ IndustryROABelowTrend ${ }_{t}$} & -0.06 & -0.04 \\
\hline & $(-0.94)$ & $(-0.68)$ \\
\hline \multirow[t]{2}{*}{ Firm - IndustryEmploymentGrowth ${ }_{t}$} & 0.06 & \\
\hline & $(0.58)$ & \\
\hline IndustryEmploymentGrowth $_{t}$ & $\begin{array}{r}-1.20 \\
(-2.23)^{* *}\end{array}$ & \\
\hline \multirow[t]{2}{*}{ Firm - NAICEmploymentGrowth $h_{t}$} & & 0.04 \\
\hline & & $(0.37)$ \\
\hline \multirow[t]{2}{*}{ NAICEmploymentGrowth $h_{t}$} & & -2.85 \\
\hline & & $(-2.95)^{* * *}$ \\
\hline \multirow[t]{2}{*}{ IsUnder $65_{t}$} & 0.18 & 0.18 \\
\hline & $(2.57)^{* *}$ & $(2.68)^{* * *}$ \\
\hline Pseudo $R^{2}$ & 0.042 & 0.043 \\
\hline No. of obs & 1933 & 1930 \\
\hline
\end{tabular}


Table 5: CEO compensation patterns. Reference event category is "no turnover at time t". All pay components are expressed in $\$$ thousands. Fama French 48 industry code fixed effects and year fixed effects are included. Standard errors are clustered by firm.

\begin{tabular}{|c|c|c|c|c|c|}
\hline & Salary $_{t+1}$ & Bonus $_{t+1}$ & $\begin{array}{l}\text { Options } \\
\text { Value }_{t+1}\end{array}$ & $\begin{array}{l}\text { Other } \\
\text { Payt+1 }_{t}\end{array}$ & $\begin{array}{l}\text { Total } \\
\text { Payt+1 }\end{array}$ \\
\hline Retirement $_{t}$, Insider $_{t}$ & $\begin{array}{r}-61.80 \\
(-5.96)^{* * *}\end{array}$ & $\begin{array}{r}-172.46 \\
(-3.69)^{* * *}\end{array}$ & $\begin{array}{r}0.74 \\
(0.00)\end{array}$ & $\begin{array}{r}-216.56 \\
(-2.28)^{* *}\end{array}$ & $\begin{array}{r}-450.07 \\
(-2.04)^{* *}\end{array}$ \\
\hline Retirement $_{t}$, Outsider $_{t}$ & $\begin{array}{r}-91.61 \\
(-4.75)^{* * *}\end{array}$ & $\begin{array}{r}114.06 \\
(1.21)\end{array}$ & $\begin{array}{r}785.94 \\
(2.13)^{* *}\end{array}$ & $\begin{array}{r}607.01 \\
(2.32)^{* *}\end{array}$ & $\begin{array}{r}1415.40 \\
(2.72)^{* * *}\end{array}$ \\
\hline Voluntary $_{t}$, Insider $_{t}$ & $\begin{array}{r}-99.83 \\
(-12.70)^{* * *}\end{array}$ & $\begin{array}{r}-142.48 \\
(-4.06)^{* * *}\end{array}$ & $\begin{array}{r}14.22 \\
(0.11)\end{array}$ & $\begin{array}{r}-123.37 \\
(-1.60)\end{array}$ & $\begin{array}{l}-351.47 \\
(-2.14)^{* *}\end{array}$ \\
\hline Voluntary $_{t}$, Outsider $_{t}$ & $\begin{array}{r}-138.88 \\
(-10.35)^{* * *}\end{array}$ & $\begin{array}{r}-153.38 \\
(-3.86)^{* * *}\end{array}$ & $\begin{array}{r}1143.53 \\
(4.05)^{* * *}\end{array}$ & $\begin{array}{l}222.17 \\
(1.85)^{*}\end{array}$ & $\begin{array}{r}1073.44 \\
(3.05)^{* * *}\end{array}$ \\
\hline Forced $_{t}$, Insider $_{t}$ & $\begin{array}{r}-94.73 \\
(-4.46)^{* * *}\end{array}$ & $\begin{array}{r}-139.98 \\
(-1.53)\end{array}$ & $\begin{array}{r}225.48 \\
(0.58)\end{array}$ & $\begin{array}{r}41.86 \\
(0.21)\end{array}$ & $\begin{array}{r}32.62 \\
(0.08)\end{array}$ \\
\hline Forced $_{t}$, Outsider $_{t}$ & $\begin{array}{r}-92.60 \\
(-3.18)^{* * *}\end{array}$ & $\begin{array}{r}58.82 \\
(0.65)\end{array}$ & $\begin{array}{r}1969.56 \\
(3.52)^{* * *}\end{array}$ & $\begin{array}{r}556.05 \\
(2.44)^{* *}\end{array}$ & $\begin{array}{r}2491.83 \\
(3.84)^{* * *}\end{array}$ \\
\hline MarketValue $_{t}$ & $\begin{array}{r}0.01 \\
(16.85)^{* * *}\end{array}$ & $\begin{array}{r}0.04 \\
(12.00)^{* * *}\end{array}$ & $\begin{array}{r}0.12 \\
(14.50)^{* * *}\end{array}$ & $\begin{array}{r}0.07 \\
(11.49)^{* * *}\end{array}$ & $\begin{array}{r}0.24 \\
(19.08)^{* * *}\end{array}$ \\
\hline $\begin{array}{l}\text { Adj. } R^{2} \\
\text { Observations }\end{array}$ & $\begin{array}{r}0.284 \\
19336\end{array}$ & $\begin{array}{r}0.204 \\
19336\end{array}$ & $\begin{array}{r}0.172 \\
19336\end{array}$ & $\begin{array}{r}0.168 \\
19336\end{array}$ & $\begin{array}{r}0.275 \\
19336\end{array}$ \\
\hline
\end{tabular}

Fama French 48 industry fixed effects, year fixed effects included 